\title{
7 \\ Tempered and diverse forms of capital
}

\section{Key propositions}

- Competition policy is a good thing when it strengthens markets in goods, and bad when it strengthens markets in bads. The remedy is to temper Donor McDonor markets with strategic regulation.

- Markets in children's books, Consumer Reports magazine, pricing carbon, software markets that protect against property crime and markets for motor vehicle antitheft technologies are among examples of virtuous markets in crime prevention. Markets in compliance professionalism and the privatisation of criminal prosecution are particularly strategic for controlling corporate crime (Chapter 9).

- High-crime cities that have deindustrialised can be renewed by renewable energy and welfare, by a green welfare economy that opens the door to a low-crime information economy (in which black lives matter).

- Old socialism and 'old' neoliberalism cannot deliver this liberating outcome. Transformation requires a hybridity of strategic publicisations of the private and privatisations of the public with an eye on freedom as nondomination.

- Regulation of the financialisation of capitalism and of tech platform monopolies is particularly imperative.

- Economic capital must be strong to accomplish a low-crime, highfreedom society, but so must be human capital, social capital, recovery capital and restorative capital. 
- While there are fertile distinctions among different forms of social capital, they are mutually constitutive. Each tempers the abuse of power by the others. This is also true of collective efficacy-a variant of social capital that is particularly strategic for crime control.

- When all these forms of capital become strong, the way they each check and balance one another creates a societal strength that is nuanced, nimble and dialogic rather than dominating.

- Mutually constitutive forms of capital in turn constitute CHIME (Connectedness, Hope, Identity, Meaning and Empowerment). CHIME controls crime.

- Without further strengthening all of the foregoing strengths, the superior capacity of authoritarian capitalism to pull levers may overwhelm liberal capitalism. A violent world dominated by authoritarianism, criminalised states and criminalised markets is our path unless we consider these hybrid paths not taken.

- Strong markets, a strong state, strong civil society and strong individuals with an agency that makes the personal political are all vital to more freedom and less crime, as are enculturating trust and institutionalising distrust in all key institutions.

- Contemporary capitalisms are highly internally variegated. Different variegations require different mixes of forms of capital and forms of regulation.

- A crucial art of freedom is to learn how to flip markets in vice to markets in virtue. Markets that control crimes of domination are an important part of that art of freedom. Institutional anomie theory is misguided if it neglects or dismisses this.

- Crashes in capital markets are connected in dangerous ways to security crises and environmental crises. Flipping to markets in virtue is one important approach to averting cascading crises.

- Markets such as Wall Street are constituted by communitarianism among traders; understanding this is a key to understanding how to flip them to markets in virtue via collective efficacy remedies such as restorative justice. 


\section{Markets in criminal bads and crime-prevention goods}

This chapter resumes the theme of how to temper anomic financial capital with checks and balances. In this sense, it picks up the institutional anomie approach of previous chapters. Where it diverges sharply from that tradition, however, is that it argues for strengthening the institutions of the market to harness markets to control crime and expand freedom. Chapter 2 introduced the criminalisation of markets as a central issue for macrocriminology in conditions of contemporary capitalism. This chapter argues that financial capital is important in the era of the financialisation of capitalism. But financial capital, like all forms of capital, becomes a better tool of freedom when it is intertwined with all the other forms of capital the chapter discusses.

Competition policy under capitalism induces some effective competition in harnessing modern management techniques to the more efficient production of bads as well as goods. This problem is structurally general. It can be illustrated with many vices such as paedophilia and its mass marketing by competing commercial exploiters of this vice through the internet, sex shops and sex tourism. Indeed, it can be illustrated with a more competitive and more globally networked market in bodies of various ages and in body parts, not only for sexual exploitation, but also for illegal immigration and for medical, cosmetic and other uses. For republicans, few vices could be worse than this darknet-enabled reinvention of slavery. Starting with the liberation of Hebrew and other slaves by Cyrus the Great of Persia and culminating with the nineteenthcentury globalisation of the ban on the slave trade, this was the greatest and the first successful global social movement for human liberation.

Examples such as the sex trade and the payment of bribes in countries where every business pays them bring into focus the question of who is to say what is vice and what is virtue? Liberal economic theory argues that more effectively competitive markets are good precisely because markets leave it to every citizen's taste to be enacted by them alone into preferences that drive the price mechanism. Why should this not apply to the price of sex or bribes, which could be economically efficient or productive in growing economies? The state, the church or political activists must not tell us what is good for us. Untrammelled choice, they say, is the essence of being a free citizen of a liberal society. 
It nevertheless remains the case that all of us have views-albeit conflicting-about what are good and evil things to do as we indulge our preferences. Mostly, these normative judgements are bound up with obligations we believe citizens should have to be other-regarding. To the extent that competitive markets succeed in delivering the more efficient satisfaction of freely chosen preferences, they will more efficiently produce bads as well as goods - however bad and good are defined. Yes, we all have different views on what is good and what is bad, what is vice and what is virtue, what should and should not be criminal. However differently we define these things, it is analytic that more effective competitive markets will more efficiently produce bads and goods, legal and illegal products and services, alike.

A paradox of a more effectively liberal economy is that it forces us to make more judgements about the vices we want the state to regulate or criminalise. Because a perfectly competitive market economy more efficiently produces vice-indeed, innovation in vices yet to be invented (such as new designer drugs, killer robots and weapons of mass destruction) - it creates greater demand from citizens for state and global regulation. Markets that are widely viewed as markets in virtue often stimulate markets in vice. Hence, Braithwaite (2005b) shows that markets in tax law advice constantly generate new shelters to protect the rich from their tax obligations. They also engender insurance markets that cover their legal liability for tax penalties should the shelter be successfully attacked in the courts. Yet Braithwaite (2005b) also shows that in reaction to this, a market in reputable tax advice is created by accountants whose main asset is their reputation with tax authorities as law-abiding, ethical tax advisors. Software markets develop products that assist the evasion and/or avoidance of tax obligations; other software products help firms to check whether they have complied with the law. Capitalism thus engenders an ever more robust contest between markets in tax vice and markets in tax virtue. The regulator's challenge, according to Braithwaite (2008), then becomes what state and civil society can do to advantage markets in virtue and hobble markets in vice.

Braithwaite (2008: 52-60) and Dukes et al. (2014) developed several regulatory principles for how to flip markets in vice to markets in virtue. These devices can be purely economic, such as taxing sugary drinks (sugar as a market in vice) and giving cheaper health insurance to consumers who take out gym memberships (gyms as a market in virtue). Instead of criminalising the purchase of dangerous drugs by children (as with tobacco) 
or criminalising use by a person of any age, an option is to tax dangerous drugs very heavily and regulate their sale heavily (by banning advertising, requiring prescriptions, and so on). Regulatory devices for flipping markets in vice to markets in virtue can also involve webs of normative and social movement influences to shift the vice-virtue market balance.

These can be combined with incentives to draw whistleblowers from inside the market in vice across to support the market in virtue. One way is to pay whistleblowers a percentage of the fines imposed on sellers who break regulatory laws, as in the US False Claims Act. We discussed in the previous chapter the evidence that bounties for whistleblowers have been a major help in enforcement against corporate crime in the United States. Another strategy is shifting enforcement targeting from perpetrators of vice to marketers of vice and leaders who cover up vice in their institutions. This is the idea that a more effective way of shutting down paedophilia than prosecuting aged priests would be to prosecute the Pope or a cardinal who heads a national church as an individual, or the church as an institution, for a new criminal offence of covering up extreme domination. ${ }^{1}$ The safety of air travel has improved so much in the past century even though pilots and air traffic controllers are very infrequently prosecuted for their mistakes or recklessness. Because the cover-up of near-misses or negligence is prosecuted, however, a culture of learning from mistakes has been nurtured (Braithwaite 2005a). The second half of this chapter adds a more structural approach to flipping markets in vice to markets in virtue through advocacy for creative balancing and tempering of financial capital with other forms of capital.

It does not matter to the analytic argument that both bads and goods are produced more efficiently by competition policies that engender vibrant markets, however good and bad are defined. This does not mean that how good and bad markets should be defined is unimportant. On the contrary, it demonstrates that criminology is dangerous without contested normative moorings. The previous chapter showed that markets stripped of a moral dimension are heartland concerns for a macrocriminology of freedom and of market anomie. Indeed, a world in which virulent markets produce vices more widely, more efficiently and more amorally is a threat to the normative order and therefore to the management of crime and unleashing of freedom.

1 Elizabeth Warren's proposal, discussed further in Chapter 9, of CEO criminal liability for negligent stewardship of a criminal corporation would be another path to prosecution of some future Pope. 


\section{Learning to diagnose criminal markets: The Philippines}

Let us illustrate the diagnosis of criminal markets by considering one society, the Philippines, which turned out to have profoundly criminal markets. This is a macrocriminological illustration of why one society can have higher levels of many kinds of crime and threats to freedom than others. There are dozens of countries with a worse homicide rate than the Philippines, but at 8.8 per 100,000 , its rate is as high as homicide gets in Asia. The estimate fails to count exceptional numbers of murders by the police. I will argue that the criminalisation of markets is an important contributor to police murders. The criminalisation of Philippine markets is a particularly important criminalisation because of the way it sustains high levels of poverty and pushes up rates of many other forms of crime.

I visited the Philippines 20 years ago with leaders of the ACCC and the Foundation for Effective Markets and Governance. Our mission was to assist the Philippines with introducing new competition and consumer protection laws and their enforcement. I came away cynical about our mission. My analysis was that there were so many higher priorities for the Philippines than getting competition and consumer law working effectively. Regulation of monopolies is a good thing, but the Philippines' problem, as I wrongly diagnosed it then, was that the country needed to focus on creating more flourishing businesses before it started worrying about businesses monopolising the economy. More fundamentally, the Philippines needed to focus on lifting poor people out of poverty and it was public investment in things like education that would achieve that.

In 2015 and 2019, when I visited the Philippines for the fourth and fifth times, I was impressed by the quality of the educational outcomes and the great progress that had been made, particularly in education for girls. The poor were still poor, however. Well-educated young people had no jobs to go to. So what was wrong now? It was my earlier analysis that was wrong. One profound poverty-inducing malaise in the Philippines was always monopoly. Companies that create jobs fail to grow in the Philippines because dominant monopolies crush competition from new competitors. Take Philippine Airlines. Why is it so much less successful, so stunted, compared with most Asian national airlines? You might think it has a massive commercial advantage over an airline like Singapore Airlines because it has a huge domestic air transport market 
of 100 million people separated across large islands. It should have been able to build a formidable international business with economies of scale on that domestic foundation compared with Singapore Airlines. The reason it has not is that political cronies long ago took over Philippine Airlines. Ex-Philippine Airline executives captured the airline regulators. The company's monopoly profits have been protected from competition; they line the pockets of political cronies.

The commercial opportunities to corrupt markets in this way are enabled in turn by political corruption. Criminalised markets induce criminalised states and vice versa. While we can easily see how one kind of corporate crime leads to another and to state crime, this hardly seems to explain high homicide rates. In fact, it does to a degree because the corrupted state often disappears people it does not like. Sometimes when the police or their political patrons do not like a little person or even a big one like a mayor, they kill them, claiming they were drug dealers or drug barons resisting arrest. Many cronies in the Philippines have become bosses of organised crime who buy impunity for their murderous activities in the market for votes that is Philippine democracy. Paul Hutchcroft (1998) described it as Booty Capitalism.

But the more fundamental connection between monopoly and murder is at the level of the local monopolies of booty capitalism. High-integrity criminal law enforcement is more important than competition law enforcement to breaking the grip of these local monopolies. Yes, there are people who dominate national monopolies, but there are other often totally different people who are local oligarchs. Frequently, this is the wealthiest businessman in a town, who buys votes to become mayor. He then uses his position to drive away any local competitor to his businesses. He drives them away either by using his political power as mayor or by threatening them with violence by a militia he controls. He also deploys their violence to keep winning elections. This means in the Philippines the monopoly power of the national airline is a small problem compared with hundreds of little local monopolies that make food, financial services, accommodation and many other things much more expensive for poor people than they would be if there were local competition. In very recent years, partial salvation for the poor who live under the yoke of these violent local monopolies of business power has been opened by e-commerce becoming more accessible to poor Filipino towns. Internet markets have therefore tempered the power of local oligarchs somewhat and have also contributed to crime prevention by helping to reduce poverty. I cannot think of many 
ways in which e-commerce dominated by the likes of Amazon is a market in virtue, but this is certainly one of them. Hence, after centuries of underdevelopment, this contestation of local monopolisation by a global market effervescence, combined with an excellent education system for girls and boys (many of whom return incomes from overseas) and natural blessings like the world's richest fisheries, began to cause job creation and growth to improve from 2005. Growth was particularly strong in 2018 and 2019. Now, local corruption and violence pose new threats to that accomplishment. An example is overfishing that is not regulated effectively by corrupt regulators. The imperative remains to incapacitate local oligarchs by criminal enforcement from monopolising local business power, political power and militia power.

\section{Accommodating markets in virtue in institutional anomie theory}

Institutional anomie theory (Messner and Rosenfeld 2013) is the extant macrocriminological tradition closest to the theory of tempered institutions developed in this book. It seeks to integrate institutional with classical (ancient and Durkheimian) and Mertonian anomie theories oriented to illegitimate opportunities and lure. The review of evidence supporting these perspectives as important to explaining crime proved encouraging in earlier chapters. The problem with institutional anomie theory opened up by the example of booty capitalism in the Philippines, however, is that it fails to consider where markets are virtuous and it fails to advocate the strengthening of virtuous markets.

The most important examples of markets in virtue are markets in decent jobs in which employees are treated with respect regardless of their race or sex. These are jobs that build the human and social capital of employees and what we describe in this chapter as CHIME (Connectedness, Hope, Identity, Meaning and Empowerment) in their journey of human capital formation. Not all jobs do this, of course. A homeless teenager who survives through sex work in oppressive conditions participates in a market in vice rather than a market in virtue. The criminalisation of markets in human trafficking is needed but is not likely to deliver as powerful a pathway out of the market in vice as programs that discover what sort of future the teenager seeks and then help place them into a job with training 
opportunities that open that pathway. Often a countervailing market in virtue offers the better pathway out of vice than the criminalisation of vice.

Many markets that constitute CHIME are quite banal, such as the market in children's books, which is not monopolistic. It is steered to virtue by wise parents sharing the good fun and developmental experiences they have with their child reading a particular book. It is a market buttressed by charities that sell such books secondhand to poor families at very affordable prices, and by a gift economy of passing on good books to those we love.

Then there are markets that are virtuous because they protect citizens from crime. At the western frontier of the United States in the nineteenth century, citizens could be terrified to enter a bank lest an armed outlaw arrive. Such unfreedom does not terrorise banking today. The banking market has restructured to diminish opportunities by holding less cash; the bank building is full of monitors, cameras and alarms that can make it impossible to escape with these modest amounts of cash. Markets in private security technologies have delivered this freedom to bank customers. As citizens prepare to drive away from the bank, theftprotection technologies make it less likely than it was half a century ago that they will discover their vehicle has been stolen. For example, privatesector automotive markets half a century ago started to perfect ignition systems that made it impossible for car thieves to steal a car without a key by 'hotwiring'. This assisted great reductions in car theft in the final decades of the twentieth century, even as car thieves began to adapt by stealing car keys from owners' homes. Car theft reduction was part of the great crime drop of the 1990s in western countries. Burglar alarm systems in cars and homes have also made contributions to preventing both kinds of theft, but much less so than hardening using engine immobilisers (Farrell et al. 2014; Weatherburn and Rahman 2021: Ch. 6). Markets in the virtue of target hardening have thus contributed much more to motor vehicle theft reduction than better deployment of police and increased imprisonment to increase deterrence (Chapter 9). The market in virtue was enhanced by consumer organisations and publications like Consumer Reports and Which around the world that produced shame lists of the brands of vehicles most prone to theft. This consumer-movement shaming motivated laggards in the market of target hardening to be more competitive and motivated government regulatory and insurer responses that mandated adoption by car manufacturers of technologies such as 
engine immobilisers. The growing efficiency of markets in electronic funds transfer has reduced the attractiveness of all forms of crime involving the grabbing of cash (Weatherburn and Rahman 2021). Markets in targethardening technologies have made it much harder to steal from a bank, a business, a home or a car, to shoplift, to counterfeit banknotes, to steal a mobile phone, to fence stolen goods or to hijack a plane, contributing variably but substantially to the great western crime drop of recent decades. Most criminologists might acknowledge this, yet criminological theory has developed in a way that mostly marginalises it as a minor issue, which empirically it is not. Our understanding of these markets is still rather confused because the effects are undoubtedly nonlinear-that is, there probably are tipping points where property offenders consider that robbing a bank makes no sense, breaking into a wealthy person's home or car makes no sense and hardening higher proportions of those targets makes no difference. Criminology fails to inform our understanding of where those tipping points might be.

Ayres and Levitt (1998) found that Lojak, a hidden transmitter used for retrieving stolen vehicles, reduced fraudulent insurance claims ${ }^{2}$ and caused a sharp reduction in motor vehicle theft, saving $\$ 10$ in reduced theft costs for each dollar spent on Lojak. Consumers who paid to install Lojak in their cars obtained only 10 per cent of these benefits. Ninety per cent of benefits went to free riders through reduced risks of car theft in cities where Lojak attained significant levels of use. This led Ayres and Levitt (1998) to propose subsidising this market in crime prevention as a cost-effective policy. That kind of policy proposal is not the way criminal justice policymakers think, so policy ideas for markets in virtue are little pursued, even in this case when the work of elite researchers (Ayres and Levitt) was taken seriously in little-cited work by the absolute elite of criminological researchers (for example, Nagin and Weisburd 2013).

Ignition interlock devices for the incapacitation of drink-driving are another technological innovation that have been shown in systematic reviews to have one of the highest effect sizes among correctional measures (Weisburd et al. 2017: 427). The huge wave of terrorist hijackings of aircraft half a century ago was all but ended during the 1980s and 1990s through the effectiveness and continuous improvement of markets in scanning technologies for use before passengers board aircraft.

2 Personal communication with Ian Ayres. 
While the private sector has driven anti-theft innovation, there has been public-sector innovation in markets in anti-theft virtue, such as the invention by the Reserve Bank of Australia of plastic banknotes that are difficult for counterfeiters to copy. Sadly, Australia's publicsector central bank adopted some private-sector vices when it sold this innovation to some countries by paying bribes to state decision-makers, including Saddam Hussein of Iraq! Credit cards also made counterfeiting a progressively less lucrative crime. But as is the story of all markets in anti-crime virtue, they inspire counter-markets in vice that are new forms of criminality. In this case, that is credit card fraud. So, we will see there is a great deal of contingency in how the competition between markets in virtue and markets in vice unfolds. The reality of contemporary capitalism is there is no escaping that competition, so there is no alternative but for societies to seek to get better at markets that design ever more effective incapacitation of access to sites of lure.

Clifford Shearing says we move from one bubble of private security to another as we travel from a bank to a shopping mall to a sports stadium to an airport or railway station, and then to our workplace. Public security provided by police comes into play only as we move between one bubble of private security and another. Under each bubble, markets in security technologies are often what protect us, though they can also be private policing markets. If a terrorist is lurking at the airport, this risk is more likely to be detected by the AI market in facial recognition than an alert police officer. It is more likely to be the private market in scanning technologies that detects their bomb or gun. These are markets that might slow our transit through the airport, but they are markets in private security that make us freer from the fear and reality of terrorism (at least in the context of boarding a plane). From reading criminology journals, one would not think those markets could be more important than prisons and police in protecting us from crime. Policing and punishment of drinkdriving are less important in protecting us from drink-drivers worldwide than the global market in road construction technologies that make it impossible for the drink-driver to veer to the wrong side of the road and crash into oncoming traffic. This technology market protects us 24 hours a day from drink-drivers who used to do this a lot. Police patrols only protect us during those infrequent minutes when their patrols intersect with our journeys. Even forms of criminal victimisation that historically had large but largely financial impacts on us, such as insider trading in shares that we or our pension fund owned, are now detected from time to 
time by software that monitors micropatterns of share price movements. Software of this kind also makes it difficult to fix consumer prices through the simple expedient of secrecy in cartel meetings, because what used to be kept secret to the naked eye is more detectable as price-fixing patterns by price-monitoring AI.

Consider the markets of vice and virtue in the challenge of climate change. While the noble exceptions are many (for example, Gunningham and Grabosky 1998; Michalowski and Bitten 2005; Ayling 2013; Shover and Hochstetler 2005; Simpson et al. 2013; Haines and Parker 2017; White 2017; Holley et al. 2018; Pali and Biffi 2019), criminology mostly neglects the duty to make criminological contributions to this existential crisis. Carbon taxes and emission trading schemes are promising ideas that have performed poorly so far in realising their promise, for many reasons. One neglected reason is that a tax on harm cannot do all the regulatory work of criminal enforcement. Sophisticated businesses cheat on taxes on harm in the same way they cheat on any tax (Braithwaite 1981). Therefore, they must be sanctioned criminally when they fraudulently misrepresent the quantum of environmental harm they submit to the tax authority. The cross-national analysis of Best et al. (2020) revealed that the impact of increasing the price of carbon is statistically significant, but one would have to say disappointingly small compared with the predictions of economic theory. The average annual growth rate of carbon dioxide emissions from fuel combustion was found by Best et al. (2020) to be only 2 percentage points lower in countries that have a carbon price than countries without. Statecraft must do much more than reduce future carbon growth rates by this amount to create a liveable future for generations to come. We must move to substantial annual percentage reductions. Hence, we look the possibility in the eye that carbon fraud is one reason these estimates are not as large as economic theory predicts, and indeed the possibility that they are estimates inflated by carbon fraud. Beyond that, there is the problem that while the European market has been the leader, it has been used mainly as a financial market for hedging and speculation that Berta et al. (2017) described as 'a bubble of compliance in a whirlpool of speculation'. Criminologists of markets in vice and virtue have a massive contribution they must make for our children's future here-likewise with countering corruption and fraud in developing-country carbon market offsets for replanting rainforest. 
Robert Agnew (2012) argues that climate change is likely to have catastrophic consequences for surging crime rates because it will push structurally anomic forces such as large population movements, armed conflicts over dwindling and contested water resources, the digging of illegal wells, illegal diversion of irrigation and attacks on those wells and irrigation systems, famines, fires, floods and other disruptions to social and normative orders. While anomie theory is highly relevant in Agnew's analysis, a limitation of the institutional version of anomie theory remains its neglect of the importance of prevention through markets in virtue. I refer, for example, to renewable energy startups who invent new technologies to harness solar power through improved panels and battery storage for electricity and new technologies to harness the power of wind, water and hydrogen. It is dubious to see nuclear power as a market in virtue; the problems of nuclear waste make it almost certainly a market in vice. But at least regulatory studies have made great contributions to showing how to reduce the risk of nuclear power production disasters through a move from punitive to regulatory controls that promote systemic wisdom about risk prevention-most notably, through the work of Rees (2009). Since the Three Mile Island incident, enforced self-incapacitation is what has made us safer from the corporate offences that cause a nuclear meltdown that could kill a million people (as discussed in Chapter 10).

With the climate change challenge, the imperative is so clear that we must develop a position on what are and are not markets in virtue, and then commit as a species to promoting those markets. Much can be learnt from how the national security state (Weiss 2014) in the United States promotes markets in the vice of more deadly weapons systems. This works not through pure market solutions but through strategic kinds of state-market hybrid collaborations/competitions among networks of firms and state agencies steered by the Pentagon (Dorf and Sabel 1998). The outcomes are mixed. This networked governance of markets has delivered markets in destabilising, anomic, new vices like killer robots to invade countries that might be produced in the millions by $3 \mathrm{D}$ printers. It also produced the internet, which is a market with many virtues (and vices). Sadly, the US Navy also developed a secure, encrypted way for its ships, submarines and the intelligence community to communicate (Swan 2016). The code for the encryption was released publicly for opensource development, but this technologically enabled the dark web to secretly sell hacking kits, drugs and sex slaves! 
Competition policy, which increases the vibrancy of markets in goods, is a good thing and an institutional domain in which corporate criminologists have important contributions to make. Yet policies to increase the vibrancy of the production of goods are only a good thing if they are counterbalanced by regulatory institutions that regulate the consequential markets in bads. At one level, this is a quintessential institutional anomie theory point to make. At another level, it exposes the need for institutional anomie theory to accommodate the imperative of the aggressive promotion of markets in virtue. American antitrust policy has contributed profoundly to the greatness of the US market for job creation and has tempered corporate power somewhat at the commanding heights of capitalism (Braithwaite and Drahos 2000: 175-218).

Monopolisation by technology giants continues to be a massive risk to all economies and requires antitrust reforms that tackle that monopolisation. Firms like Facebook pose grave risks to freedom. In the long run, nevertheless, US competition policy has done a useful job of stoking the vibrancy of the American information technology (IT) sector. This started early on with the monopolisation cases in the United States (and Europe) against IBM, which once was number one on the Fortune 500 list of the largest corporations and once dominated IT as an unassailable colossus. Forty years ago, Fisse and Braithwaite (1983) interviewed key players in these accomplishments, like Nicholas Katzenbach, who was attorney-general in the Johnson administration. Katzenbach launched the early monopolisation cases against IBM. At the time of our interviews during the administration of Jimmy Carter, he was employed by IBM as its vice-president and general counsel! The accomplishments of this early antitrust enforcement more generally were criminologically profound, yet ignored by deterrence scholars in criminology. Waldman's (1978) research, reinforced by Fisse and Braithwaite's (1983) on IBM and other cases, showed there were profound specific deterrence effects that were achieved long before any penalties were imposed, and before cases went to court. Monopolists like IBM prepared for their impending antitrust cases by transforming their antitrust compliance policies and, in some instances, by divestitures in advance of cases that they feared could lead to forced divestitures by the courts. Specific deterrence worked in advance of punishment because enforcement strategy gave time for markets in virtue to rally and reconfigure markets in vice because of the anticipation of a possible future penalty from the regulatory state. Chapter 9 discusses the broader importance of deterrence that precedes rather than follows 
prosecution. IBM long ago ceased being an IT monopolist. The vibrancy of US competition in this sector allowed many new firms to enter the market and clip IBM's wings. Today, IBM competes with contemporarily more formidable monopolists by being a champion of machines integrated with open-source software, which is one best hope for breaking these latest monopolies.

Rose-coloured glasses cannot obscure the less illustrious accomplishments of US antitrust law under the Trump administration. Nor can we use rosecoloured glasses to look at regulatory state accomplishments against IT markets in bads more broadly. Yet, at a structural level, notwithstanding its neoliberal rhetoric, the US state has accepted the imperative that if it wants the benefits from the most vibrant IT economy in the world to continue, its capabilities for regulating cybercrime must be improved. Undoubtedly, it has not performed as well as consumers would like in keeping up with the entrepreneurship of cybercriminals with regulatory entrepreneurship. Yet it does accept the imperative for a regulatory state that works hard at the task of trying to catch up. And this is a general criminological imperative, not just one about cybercrime. Markets in virtue can do good for humankind, including in crime prevention, but it is an iron law of markets that markets in goods will be gamed into markets in bads. This means the benefits of markets in goods will be lost if the criminological imagination fails to mobilise to the challenge of regulating markets in bads.

This argument started with a consideration of the most virtuously important market for human survival and flourishing: new markets in renewable energy. These inspiring renewables markets are also making electricity available for the first time for students to do their homework at night in thatch-roofed houses in the most remote, impoverished villages of our planet. Lights and laptops are powered by tiny solar panels for each dwelling. Let me, then, conclude this section with a reminder of the virtues of a great environmental law enforcer from an earlier era, US President Ronald Reagan, who mobilised markets in environmental virtue. I refer to the regulatory accomplishment of President Reagan in ordering his ambassadors to persuade - or coerce, if necessary—other states to sign the Montreal Protocol on ozone-depleting substances in 1987. Thanks to the Reagan administration, and to American markets in virtue, the Montreal Protocol became the most effective international environmental 
agreement, the best enforced one and one that has saved hundreds of thousands of human lives (Kuttippurath and Nair 2017). How was this accomplished (Braithwaite and Drahos 2000: 261-67)?

In the first instance, it was an accomplishment of strong American civil society in the form of an environmental movement securing a ban on chlorofluorocarbons (CFCs) before Reagan came to power. Environmental movements in the rest of the world had been unable to accomplish this. The US chemical industry rose to the challenge of the regulatory ban by competing in a new market in the virtue of CFC-substitution technology. After DuPont won that competition, it went to Reagan with the argument that it would be good for US business to force the rest of the world to also ban CFCs. Failing to do that would mean US manufacturers would be disadvantaged by being hobbled with more expensive green technology. Conversely, forcing the rest of the world to follow the US to more demanding environmental standards would give DuPont (and upstream and downstream American suppliers) a strategic trade advantage over their European, Japanese and Chinese competitors. The chemical giants of these economies would be pushed to buy licences for the new CFCsubstitute technology from DuPont. And so, a successful and implausible coalition of Reagan, the US chemical industry and environmental NGOs in Europe, Japan and the rest of the world assembled to lobby country by country to get signatures on the Montreal Protocol and then to enforce it after 1987. The lesson of Montreal is that the weak can prevail against the strong in the world economy when civil society groups harness strategic trade theory to divide the strong, turning markets in business virtue against markets in business vice, breaking off bits of business solidarity and harnessing them to projects of the good society. This is accomplished in harness with strong states with strategic trade interests aligned with markets in virtue.

A strategically comparable accomplishment also opened up in the previous chapter was that of Christian churches in the British Empire, at a time when North America was part of that empire, in the movement that banned the slave trade (Braithwaite and Drahos 2000: 498-501). Once Britain and its colonies surrendered to the political power of the churches among the ranks of the British Parliament's lawmakers, Britain had a strategic interest in defending the competitiveness of its colonial plantation economies by forcing the other colonial powers (Spain, Portugal, France) to cease international slave trading. One way it did this was by using the regulatory power of the British Navy to prevent foreign 
slaving ships from entering the harbours where new slaves were sold. This is theorised as an incapacitation accomplishment of the British Navy in Chapter 10, rather than a deterrence accomplishment.

A big conclusion of this book is dramatically illustrated by the Montreal Protocol and international slave trade case studies: few of the best things criminology can achieve occur through criminal punishment. Rather, they are achieved by harnessing strong state regulatory enforcement (which usually has a preventive quality) to strong civil society activism and to markets in business virtue-and sometimes to preventive international law as well. Because markets in virtue tend to be global in contemporary conditions, criminology, and institutional anomie theory in particular, must not only overcome its neglect of the possibilities for enhancing freedom by embracing markets in virtue, but also overcome criminological neglect of international law. To date, the limits of institutional anomie theory are profound in these respects. This is well illustrated by mixed results from studies that have used the Heritage Foundation's Index of Economic Freedom as a measure of institutional anomie theory's idea of the subordination of other institutions by markets (for example, Bjerregaard and Cochran 2008; Hughes et al. 2015). This is a variable that is a measure of neoliberal freedom that lumps together markets in vice and markets in virtue in one indiscriminate measure. It also rejects the regulatory state (seen in Heritage Foundation thought as an antithesis of freedom). This book argues that the regulatory state is central to securing freedom.

\section{Balanced capital formation}

\section{All economies are mixed}

Why would someone who values nondomination embrace a form of capitalism that is tempered by institutional checks and balances? The embrace macrocriminology must consider in contemporary conditions is simultaneously of market and public values or, more precisely, of balanced capital formation and balanced state growth, of balance in the mix between privatisation and nationalisation (or rather between tempered privatisation of the public and publicisation of the private) (Freeman 2003). Freedom is enhanced by rich and plural policy conversations about strategic publicisation of the private and privatisation 
of the public. This book aims to identify how to temper the dangers of capitalist markets that must be regulated when competition policy fails to energise markets in goods as much as markets in bads.

In the next section, we consider why those who believe in liberty have little choice but to sustain capital formation if they are to realise their political objectives. It argues that neoliberal capitalism faces serious competition from authoritarian capitalism, which has outperformed liberal capitalism in markets this century. The argument is that the way authoritarian capitalism can lose in this competition is for neoliberalism to transform itself into a more tempered form of capitalism with a stronger welfare state, effective regulation and redistribution and financial capital formation that is tempered by robust human, social, recovery and restorative capital formation. Conversely, if China wants to win, it must temper its authoritarianism by taking Sun Yat-sen more seriously. In short, what is necessary for the survival of liberal capitalism against authoritarian challenges is a republican freedom of tempered markets in vice and invigorated markets in virtue that also increase the likelihood of a low-crime society.

This balanced capital formation analysis appropriates much from Merton and from Messner and Rosenfeld. We have seen already that one difference is that it makes distinctions between markets in virtue and markets in vice, healthy and unhealthy exercise of state power and healthy and unhealthy forms of community and normative order in civil society. The ideal is for healthy power in markets, states and civil society that are each tempered by healthy power in the other institutions, where health is assessed in terms of the contribution to freedom as nondomination. Another difference of the freedom theory of crime is that market power so tempered is something that it is healthy to strengthen, just as it is healthy to strengthen tempered state and civil society power. The final difference with the freedom theory of crime is that theoretical value is found in distinguishing financial capital, human capital, social capital, recovery capital and restorative capital - all of which are deployed to strengthen the integration of normative theory and explanatory theory. This tempered amalgam dissolves fear of an overly strong state or excessive commodification by markets in favour of the promotion of a strong state, strong markets, strong civil society and strong individuals. Each of these must temper the excesses of the others. 


\section{Capital formation}

Social democratic activists must be as seriously engaged as those on the right with the challenges of how to promote capital formation. This is required to be intellectually serious about reducing inequality and domination and the predatory crime these induce. Social democratic disappointments like Tony Blair and Bill Clinton did embrace markets. They were timid, however, about state regulation of markets, timid about a strong welfare state, about quality public housing and free education for the poor and about nurturing progressive social movement politics that offered critiques of their abuse of state power. Differential association theory might suggest their friendship networks were infected with markets in vice in the form of sometime-friends when in power like Rupert Murdoch. ${ }^{3}$ Murdoch was Thatcher's key ally in the militarised union suppression that succeeded after the miners's strike in destroying British union power. Murdoch led the crushing of journalism with a social democratic sensibility; and Murdoch was George W. Bush's key ally in the military adventurism of Afghanistan and Iraq, which Blair and Hillary Clinton so pliantly supported. A small part of social democratic excellence is averting overregulation of capital; a much larger challenge for social democratic excellence is avoiding being overregulated by capital.

This chapter will first consider financial capital, then human capital, social capital, recovery capital and restorative capital. Crime prevention is difficult without the creation of more of all these forms of capital. Accomplishing this is not rocket science; most societies can point to many of their local communities that accomplish all these things rather well.

3 I say 'sometime' because Rupert Murdoch has been on and off in his support for Hillary Clinton, depending on who was in power, and has not returned calls to Tony Blair in recent years, allegedly because of a relationship that became too close between Blair and Murdoch's former wife Wendi Deng. Murdoch accuses Deng of being a Chinese spy who used him to get close to Donald Trump's daughter Ivanka. The FBI warned the Trump family about this, if one believes Murdoch's Wall Street Journal (O'Keefe and Viswanatha 2018). Bill Clinton, of course, had even more unsavoury differential associations with Wall Street vice in the form of Jeffrey Epstein, who offered him financial stabilisation advice when he was in the White House and frequently provided his corporate aircraft to Clinton for fundraising for the Clinton Foundation after he left the White House. Murdoch's influence across the West and beyond is based on two simple business insights. One is to befriend and support through media influence whoever is in power or is likely to win it (differential association of the power of capital with the power of political winners). The other insight is that there is more money to be made by telling media consumers lies they like to hear than there is in quality journalism. Facebook adapted this insight with even greater market success. 
Crime prevention also requires changes in how we balance these different forms of capital and how we redistribute and regulate them so they are constitutive of virtuous institutions.

As robots and computers led by AI take over more functions previously undertaken by humans, some of us may struggle to find meaning from useful work that also lifts our family out of poverty, especially if we work for tech giants like Amazon. Rupert Murdoch also invented the idea that selling media lies to market segments that want to hear those lies is more profitable than selling truthful, quality journalism. That idea was then picked up by social media AI on platforms like Facebook and Twitter. AI was a market in virtue when it guided surgical robots to search for cancers more cleverly than could doctors, but a market in vice when it searched for lies more cleverly. It is a market in vice if it trains killer robots to kill every person in a militarised uniform (bus conductors, police, Salvation Army officers, hotel porters, firefighters). Learning to work with killer robots is a scary form of human capital because it is such a powerful joint product of a market in vice and what have to date evolved as disciplinary monocultures of AI in white western universities and tech firms, and Chinese versions of them. At the same time, we know that many decent scholars struggle to make AI more relational, more interdisciplinary, less monocultural, plurally grounded beyond lessons from neuroscience, and better regulated (for example, Lee 2020; Crawford 2021).

We saw in Chapter 4 that the evidence of the impact of short-term technological unemployment on crime is voluminous and contradictory. It is clearer that long-term unemployment induces lost hope and meaning and is therefore positively associated with crime even in time-series data. It is clearer still, according to Chapter 4, that individuals who come from families that experience long-term unemployment are more vulnerable to crime, and it is evident ecologically that those parts of cities where poverty, inequality and long-term unemployment are most concentrated are the areas where crime is high. Indeed, there is a multiplicative, not just an additive, effect on crime, of being a person cut off from opportunities created by capital formation and living in a community cut off from investment.

Technological change so far has not produced massive unemployment. It has casualised employment, helped reduce the share of wages in national income and produced reduced security for challenging jobs that require initiative. This happened with the loss of industrial and middle-class 
clerical and administrative jobs. Jobs with CHIME have been replaced with huge growth in the low-paid service industry work of a precariat who sell food and beverages to and clean the homes and hotel rooms of the minority who enjoy high pay. Jobs have also moved to those who work in private security to protect the valuables of those included in the new economy from the predations of those excluded. These employed people who live in poverty and have work with low meaning are a large part of the working-class political base built by Donald Trump and his breed of new far-right leaders across the West. While the new economy has not made jobs scarcer so far, it has made meaningful jobs scarcer and decimated those kinds of employment that save the humblest half of families from poverty and indignity. This book is partly about why such a world of growing inequality and declining meaning could pose a threat to the world's long-run decline in violence and crime rates (Chapters 2, 3; Pinker 2011). In the case of the Trump administration, that threat was mediated by several specific steps towards a criminalisation of the state and markets and corruption of the separation of powers. Another threat of predatory crime and unfreedom could come with economic crashes that crash more deeply.

The worst-case threat here is less crime than war. Economic crisis, particularly hyperinflation, fosters a resentful underclass and the rise of violent extremism. Braithwaite and D'Costa (2018) have shown that one thing crime and war have in common is they are cascade phenomena rather than displacement phenomena. If war were a displacement phenomenon, when we end a war in one country, this would cause war to be displaced to another country. War is not a displacement phenomenon in this way. At various points in this book, we show instead that war is a cascade phenomenon: unresolved wars cascade to more wars in that country and in neighbouring countries. Conversely, successful peace processes help neighbours to become more peaceful, enjoy lower crime rates and enjoy more employment through improved economic conditions. Bad neighbours who fight wars can cascade to us having a lot of war, crime and suicide. Crime is also not a displacement phenomenon: when we reduce crime in one locale, that tends not to increase crime in neighbouring locales, but to reduce crime there as well.

This macrosocial danger of a cascade from economic crisis to war, authoritarianism and crime is a theme that is discussed in more detail in Chapter 11. 


\section{Variegated capitalism and crime-war cascades}

Today capitalism is more variegated than ever (Brenner et al. 2010; Peck and Theodore 2007; Dixon 2011; Jessop 2015). We have no alternative but to imagine a future form of capitalism quite different from that currently dominant because neoliberal capitalism has limited sustainability. Authoritarian capitalism, as in China, is an alternative that leaves little space for freedom. One possible context for macrocriminology is a suspicion that we may be approaching, or have already passed, peak globalisation and peak neoliberalism, as the world ponders lessons from the carnage of Covid-19.

The fastest-growing economies since the Global Financial Crisis have not been the neoliberal economies. That is not to say that the world will return to the lower levels of international trade and the higher levels of national industrialisation policies of the Keynesian decades after World War II. The fastest-growing economies since the Global Financial Crisis have been large authoritarian capitalist economies like China and Bangladesh, which for decades have been growing at two or three times the rate of neoliberal economies. Since the Global Financial Crisis, even more middle-sized authoritarian crony-capitalist economies—such as Cambodia, Vietnam and the Philippines-have also grown at two or three times the rate of the western economies. Many of the biggest countries, from China and Russia to Bangladesh and now Brazil, and many high-growth small economies as well, from the United Arab Emirates, Qatar and Israel to Singapore, have rejected liberalism in favour of their own versions of authoritarian capitalism. Shifts from neoliberal to authoritarian capitalism have been particularly sharp since the Global Financial Crisis in Eastern European economies such as Poland, Hungary and some former Yugoslavian republics. Some large economies are doing well as they move away from authoritarianism towards an intermediate position between liberal and authoritarian capitalism: examples of this kind of high-growth economy are Indonesia and India (at least until it was savagely devastated by the Covid crisis). Others, like the United Arab Emirates and the Philippines, are recording strong growth as they move in the opposite direction, towards a more authoritarian hybrid of capitalism. And Donald Trump rejected neoliberalism in favour of his distinctive version of a shift in a more authoritarian capitalist direction for fortress America. 
Neither authoritarian capitalism nor neoliberalism is an attractive extreme from a crime-control perspective. Yet this book will argue that there are many versions of variegated capitalism on offer, some of which have more attractive features in terms of crime and domination prevention.

One macrocriminological argument of this book is the obvious one that growth in financial capital and redistribution of its fruits are critical to accomplishing a low-crime society. Most of the societies with the lowest homicide rates during the past half-century have been Western European and East Asian economies that have sustained high rates of capital investment and growth across many decades. At the other extreme are states that became so criminalised they were spurned by investorsdomestic and foreign. An example is a country that for most of this century has been the poorest performer in economic growth and at the bottom of the Human Development Index: Democratic Republic of Congo (DRC). Capital investment collapse caused by criminalisation of the Congolese state cascaded from crime to war and then from war to more crime, particularly to exceptional levels of rape (Braithwaite and D'Costa 2018: Part I). We will never know the homicide rate or the robbery rate in DRC. Peacebuilding Compared fieldwork in DRC suggests most homicides and robberies in eastern rural areas, where so much of the population lives, are not recorded by the police. The survey evidence on the risk of rape in DRC is staggering, even though those who conduct the surveys cannot get to the remote rural villages that are not connected to cities by roads, where the risks of and impunity for rape by armed groups are most profound.

As well as mass unemployment leading to war-crime cascades, there are many familiar examples of hyperinflation having this effect, from Germany in the 1930s to Serbia in the 1990s (Braithwaite and D'Costa 2018: Part I). The cascade from hyperinflation to violence is mediated by classic anomie. Economic collapse is not the only macro-risk that can unleash crime-war cascades today. Environmental collapse or a nuclear exchange in Asia could also disrupt the normative order by inflicting famine on many hundreds of millions of people-mostly in China in the case of an unintended India-Pakistan nuclear exchange-and insecurity for an entire region.

If a catastrophic political crisis between North and South Korea, or India and Pakistan, happened to coincide with a stock market crash and an environmental crash, perhaps no power could hold back a global crimewar cascade. That is unknowable, just as it was unknowable until 2020 how 
global the economic destabilisation could be from a modern pandemic before our universities and drug markets discovered vaccines. Yet I still suspect it is not too late to reinvent capitalism, to reinvent environmental diplomacy, disease diplomacy and war diplomacy so that a coincidence of these kinds of catastrophes becomes an event of low likelihood. That is not to say it is probable that capitalism and diplomacy will be reinvented in these ways. It is just to say that political paths to transformation and prevention are available if active citizens have the wit to take them. Even if authoritarian capitalism is in the box seat to become the successor to neoliberal capitalism, the alternative somewhat less disastrous paths are many. These alternatives are paths that regulate capitalism to secure freedom to varying degrees.

China might be better able to recover from a financial or pandemic crash than the western economies that suffer the knock-on effects on world trade from a crash in China. The authoritarian regime in China may well have better control of the levers to direct the capital investment needed to quell the crisis. After a huge crash on the Shanghai Stock Exchange, China might wobble a bit, 100 million people might lose their jobs, but the regime might be prepared to do what it takes to keep control of those levers. The regime might not fall. In contrast, elected western governments could topple like dominoes in response to a future crash that is bigger than past crashes because China spikes down and does not save the day in the way it did after the 1998 Asian Financial Crisis, the 2008 Global Financial Crisis and the Covid crisis. Some of those western governments may fall into the hands of Chinese-style, Putin-style or Trump-style authoritarian capitalism, or even more radical despotism. The Chinese financial system has profound weaknesses in integrity that render it vulnerable to future crises. Yet the western assumption that China's vulnerabilities will increase the impetus towards democracy seems hard to justify when in significant ways China is becoming more rather than less authoritarian (especially with regard to the surveillance of its citizens) as it gets stronger.

This risk warrants reflection because trust in western governments has been declining steadily across the decades since trust has been measured (Citrin and Stoker 2018). In the United States, as discussed in Chapter 3, this decline in trust had an intergenerational dynamic that was particularly strong for the Vietnam War generation in the 1960s and 1970s and for the Iraq and Afghanistan war generation this century (van der Meer 2017: Fig. 4). Trust cannot decline forever without ultimately triggering a political crisis. Real wages cannot keep declining forever as workers 
watch the rich become the super-rich without this eventually catalysing a crisis. These are just some of the dynamics behind the empirical finding that economic crises destabilise democracies more than they destabilise dictatorships (Przeworski et al. 2000). 'What stands out first and foremost' from reviews of the evidence of the global decline of trust in governments is that political trust is highest in illiberal regimes such as Uzbekistan, China, Azerbaijan, Qatar, Singapore, and Malaysia. These high scores are a consistent finding' (van der Meer 2017: 7). While China is less buffeted by a blizzard of distrust than the United States, it is still vulnerable to the same dynamics. There has been some decline in trust in government in China and this is deepest in the regions where income inequality is most extreme (Yang and Xin 2020).

The risk of a mega-crash will persist unless working-class people get a lot more money in their pockets to maintain demand for job creation. More crashes like that in 2008 will be a risk unless working people are given enough income to avert a resort to overburdening themselves with debt that causes a crisis for them if they suffer a setback in their life, and a crisis for capitalism when enough of them suffer that setback at the same time. The risk is magnified further when the regulatory system mismanages this. Mercifully, wise economists did persuade many reluctant political leaders globally to put more money into the pockets of the poor immediately after the 2008 crash and the 2020 Covid crash. Without this, these crises would have been much more catastrophic. The decline in the capacity of states to collect tax from wealthy individuals and corporations cannot go on forever without causing a fiscal crisis and a deeper rebellion of the middle class than that described by Farrall and Karstedt (2019). US President Joe Biden's new Treasury Secretary, Janet Yellen, has now recognised this risk publicly and urged international agreement to increase taxes on corporations and the rich. When the next big crash comes in the later years of the 2020s or the 2030s, western states might have less capacity to deploy fiscal surpluses or reserves because debt levels have not recovered from the 2008 and 2020 crises. At the same time, the corporate sector might lack the capital reserves to privately reprime the pump (even though financial regulation since 2008 has done some invaluable work in mandating that the largest banks have bigger reserves).

Crises of demand can be averted by creating much needed jobs in the health, education and welfare sectors, but only if fiscal crisis is averted. States need to make their tax systems work better so they have the funds to hire those new workers as they pay down the debts from 2020-21. 
Cross-nationally, the data suggest that societies with larger welfare states, controlling for other variables, have lower homicide rates (Lappi-Seppälä and Lehti 2014: 212; as discussed in Chapter 4). While collapses of capital formation are preventable, when they do happen, authoritarian capitalist regimes may survive them, while liberal capitalist regimes may fall. This means that sequences of crises-whether mediated by financial crime, a nuclear exchange, a pandemic or climate change-might ratchet the world in the direction of authoritarian capitalism. That in turn risks a positive recursive surge in corruption, various forms of state crime and unfreedom, in turn feeding back to more crime of other kinds on Wall Street and Main Street.

European criminology has been afflicted with a myopic kind of comparativism that is obsessed with comparing contemporary Western Europe with the United States and nowhere else, at no other time. This is too narrow a space-time lens for a rich macro-comparativism that comprehends crime and freedom. One problem with this European tradition is that the United States is a big place. There are larger differences within the United States than the differences between Western Europe and the United States on many variables that matter. This is true, for example, of how equitable is the distribution of the types of capital discussed in this chapter. There are small low-crime states like Vermont that are richer than Europe in restorative capital. Then there are larger states like Minnesota and Wisconsin that have higher levels of social capital, according to Putnam (2000), and richer restorative capital than most of Europe, lower unemployment rates, fewer people in poverty and large regions with crime rates lower than most of Europe. Putnam (1993: 35) conceives of social capital as the 'features of social organizations, such as networks, norms and trust that facilitate action and cooperation for mutual benefit'. Exceptions to the patterns Putnam (2000) identified are the deindustrialised districts of the largest cities of Minnesota and Wisconsin where there were such huge 'Black Lives Matter' uprisings in 2020. Minnesota abolished capital punishment in 1911 and Wisconsin in 1853, long before all but a couple of European states. Yet nearby are communities like St Louis and Detroit with among the highest crime rates of any cities in the western world, deindustrialised and devastated by the homelessness worsened by the Global Financial Crisis and the Covid crisis.

Imagine that it might be right that the world economy is passing peak globalisation. On the positive side, this could mean we move rapidly from economies that import oil, gas and coal in ships to economies that 
build new factories to produce hydrogen power, solar panels and storage batteries and lots of meaning-making blue-collar jobs in their maintenance and connecting them up to continuously improving batteries. Threedimensional printing and factory robots could make these components cheaper to produce in Detroit, close to where the panels need to be installed. While there are fewer jobs in renewables than in Detroit's old industrial capitalism, there is still a good number of them. There is even a good number of low-skill jobs in tree planting and urban agriculture that must be surged at times of crisis, just as happened during the New Deal. Companies like Ford might go bankrupt in Detroit, but new companies building electric or hydrogen cars, or parts of them, might be encouraged by the state to invest in the city. And some of the public investment to build new driverless electric public transport systems might also intentionally be directed to Detroit because it is so desperately deindustrialised and because it has been the city in the US with the worst crime rate for a good part of the post-industrial period. Public investment in rebuilding the crumbling infrastructure of the United States, which President Trump made a good case for prioritising during his 2016 election campaign (without doing much once elected), can be concentrated in cities like Detroit that have been caught in a vicious spiral in which high crime rates deter investment and disinvestment further fosters crime. In this sense, as well as the sense of slavery legacies, Detroit's violence dilemma has much in common with the dilemmas of a country with the rich potential of the DRC.

Contra-Donald Trump, a reinvention of Detroit as a restorative city (which is happening) and a regenerative city can be complemented by the massive investment in the welfare state needed in the United States. This must be a central plank of transformation to make its economy a sustainably more flourishing lower-crime economy (as discussed in an evidence-based way in Chapter 4). This means building hospitals, health centres and aged care homes with improved investment in infection control (the need for which became evident during the Covid pandemic), which are highly labour intensive. It means investment in restorative justice programs and recovery capital programs that also intensively use the labour of local people. Public investment in the building of human capital by constructing new vocational training centres in disadvantaged communities is particularly imperative. The joint investment of a new type of capitalism in new-economy factory technologies, rebuilding depleted public infrastructure and building the welfare state can together attract a boom in service-sector jobs to revive deindustrialised cities. Once 
a developmental capitalist state jumpstarted a city like Detroit to become a safer place, it can attract droves of tourists to see the old industrial monuments of Henry Ford's production lines and the Motown creative scene born at its industrial zenith. Foreign students can be attracted to use its transport and service-sector infrastructure to enrol in Detroit's tertiary education institutions. Then a new entertainment Motown for a new century might be reinvented in Detroit as a restorative, regenerative city. Methodologically, what I am doing here is selecting Detroit as a leastlikely case (Eckstein 1975) in the West for transformation to tempered, balanced capitalism, and then arguing that the needed transformation really could work well there.

Most readers will think it naive to conceive of massive reinvestment in the welfare state as politically possible. In the face of new technologies eliminating jobs and ever stronger challenges from authoritarian capitalist economies, it is hard to conceive of western capitalism surviving without a huge increase in job creation in health and welfare. So, we see the world today in a way that has similarities to the way Otto von Bismarck viewed it at that other highwater mark of economic liberalism in the late nineteenth century. Bismarck feared Germany was likely to descend into crime-war cascades, economic crises and ultimately into an authoritarian communist takeover unless it invested in building a welfare state. Hence, his government was indeed the first mover to build the welfare state in a serious way.

A more egalitarian world can also be helped by a viable strategy for gradually persuading more countries to sign International Labour Organization agreements to progressively increase their minimum wages, protect the labour rights of women and more (Marshall 2019; Quiggin 2019: 249-54), as also first happened soon after Bismarck's death. Today, it can be enhanced by a 'participation income' (Atkinson 2015; Garnaut 2021). The redistribution of profits from capital to labour would put more money in the pockets of workers to purchase more services from more service industry workers in depressed communities, as discussed in the pages that follow.

From a macrocriminological point of view, there is an imperative for macroeconomic reform and global regulatory reform, but also for state steering of investment to struggling communities like Detroit and for a local regenerative capitalism of cities, towns and villages. Growing the welfare state in a place like the Philippines or Detroit requires collecting 
more tax revenue. There are many ways this can be done. One way is through steeply progressive land and property taxes. For environmental sustainability, it is also imperative for the tax system progressively to steer the rich into smaller mansions and smaller downtown corporate offices. We know how to reverse the long-run decline in corporate tax revenue by reforming tax-enforcement policy (Braithwaite 2005b).

In the era of industrial capitalism, it was much harder to tax industrial firms heavily because of fear they might shift their factories offshore. Australia is like most economies in that the firms with the biggest market capitalisation are no longer industrial or mining firms. Nor are they global internet giants, as is true for the United States. They are all banks. The financialisation of capitalism means that, today, banks and other financial institutions such as pension funds own the industrial and service industry firms. So, it was good fiscal policy for Australia's conservative government led by a former investment banker, Malcolm Turnbull, to impose in 2017 a mega-tax only on Australia’s five biggest banks, which own so much of the country's industrial and mining firms and which benefited from state largesse during the Global Financial Crisis. Australian banks cannot credibly threaten to move offshore in response to such taxes on capital. Hence, their wealth can be redistributed to build a stronger welfare state. Likewise, the wealth of those with multiple millions of dollars locked into defined-benefit pensions cannot be so easily whipped out of that pension fund and shifted offshore. It follows from the financialisation of capitalism that the largest banks in big economies are indeed too big to fail. ${ }^{4}$ One reason is that banks create markets in virtue when they transfer money from savers to investors who make new ideas and opportunities happen. Yet we must prevent the steep multiplication of US political campaign contributions by banks in recent decades (Acemoglu and Robinson 2019: 481) from persuading politicians to privatise capitalism's profits and socialise its losses (to the tune of US\$15 trillion in taxpayer support in 2008). The sheer size of the bailout of rich bankers by taxpayers of modest means was a huge new source of inequality, as former Bank of England Governor Mark Carney pointed out in his BBC Reith Lectures. In one important sense, Prime Minister Gordon Brown did a better job in the United Kingdom than President Obama in the United States of bailing out his banks during the Global Financial Crisis. Unlike the United

4 It can make sense for a tiny economy like Iceland to allow its banks to fail because of their exceptionally deep insolvency and to allow new banks to grow from their ashes. In general, however, confidence in the survivability of banks is good for capital markets and for long-run job creation. 
States, the United Kingdom insisted on taxholder equity in failing banks like Lloyds; these shares could be sold when the market inevitably rose again. Even if the British taxpayer does later sell these shares at a loss, the shortfall can be made up later still by a special tax on banks of the kind Australia imposed in 2017. In their own ways, both Brown and Obama showed that a resort to socialist solutions can save capitalism in a major crisis—as leaders of all political hues showed again in their big-spending, big-state responses to the Covid economic shudder. This returns us to the point that if China and other authoritarian capitalist states are willing to pull socialist levers to deal proactively with smaller and larger crises, and neoliberal economies like the United Kingdom and the United States are reluctant or slow to do so, China will continue to recover from economic crises in better shape than the West, as it did in 2008 and 2020. The authoritarian capitalist economies may survive best and then dominate.

The optimistic point, however, is that in the new conditions of capitalism there is no longer a need for despair about the impossibility of a combination of tax policy, labour law and welfare policy creating much more egalitarian societies than we currently have. Chapter 4 assessed the evidence that societies with less inequality and less poverty have both less crime and less war than very unequal societies and are at less risk of crime-war spirals of the kind Europe saw in the 1990s in Serbia, Croatia, Bosnia and Kosovo. They also have better prospects of long-run capital formation, job creation and freedom.

To conclude on financial capital, we do need to grow it and to protect it from crises that might cause violence through mass unemployment or hyperinflation. Capital formation must be carefully attended to, and in a way that shakes off the shackles of old neoliberal and socialist ideologies, if we are serious about creating new job opportunities for the poor.

Creative new public-private hybrids, publicisations of the private and privatisations of the public are imperative for a form of capitalism that underwrites freedom. Chapter 9 argues that criminology must be part of this renewal when it argues that radical new privatisations of criminal prosecution are imperative for taming the enslavement of Main Street by corporate crime.

Part of the recurrent crisis engendered by financialisation is that debt substitutes for welfare. For example, instead of having nationalised health guarantees for all citizens, less than wealthy people are forced to borrow if they have a health catastrophe. Instead of guaranteeing public housing 
for the poor, credit is made more accessible for the poor to buy their own homes with backing from devices like derivatives in subprime mortgages. The problem is that when a crash occurs, a host of new problems afflicts the poor because they become homeless (and often unemployable) when they cannot pay these debts. Sadly, their children suffer even more from their parents' long-term unemployment. In the United States, there has been a dual pincer movement against the poor by substitution of debt for state welfare. It was followed by a collapse of the corporate welfare system of private pensions and health benefits that substituted for state welfare failure, as employment was deindustrialised and casualised for the working class. This coincided with a decrease in the share of wages in national income, especially the share of working-class wages. That in turn means financial capital keeps demand up to keep the economy growing by replacing demand from working-class income with demand from working-class debt. This accelerates a vicious spiral of welfare/wages to debt. The long-run formula for lower crime rates repairs this institutional damage not only by repairing the regulation of financial capital, but also by rebuilding the institutions of welfare and labour market rights. The minimum wage is at the heart of this, as is decasualisation that guarantees rights like sickness benefits.

\section{Human capital}

To reduce crime and imprisonment rates, societies must grow their human capital as well as their financial capital. The combination of strong human capital and strong financial capital should be greater than the sum of its parts, as illustrated in the earlier discussion of the strong growth of human capital in the Philippines but weaker growth in quality jobs for graduates as a strain factor for individualised anomie. So, financial capital formation is necessary for human capital formation, and vice versa. Doing well at school is a potent protective factor against delinquency (as we saw in Chapter 4). Going to university is a protective factor for preventing young people who are bullies at school from becoming physically violent young adults (Homel 2013). Societies that redistribute human capital so that more poor children do well at school and university, by simultaneously growing and redistributing human capital, can reduce crime even more. Correctional interventions that seek to improve educational, vocational and job-placement opportunities for offenders have good effect sizes in preventing crime (Weisburd et al. 2017: 425-27). 
Reducing the number of children who fail in school is achieved not only at the microlevel, child by child; it is also achieved in a more macro way by transforming the institutional character of schooling. Chapter 4 argued that schools of a generation ago were less restorative and less redemptive than contemporary schools; they were more the mouse race that prepared us for the rat race. Perhaps in some ways disciplinary schools prepared workers for the discipline of the factory and prepared middle-class organisation men for clawing their way to the top of industrial capitalism. This is definitely not the way to prepare human capital for an information economy. While the divisiveness and demoralisation of this mouse race were extreme, much contemporary practice also structurally fosters hubris or despair. In redemptive schooling that builds the human capital of the poor, students compete against their own past performance more than against other children. They are motivated by the intrinsic rewards of learning that makes their life better. Restorative schooling, as discussed under the heading of restorative capital formation, is about children learning by supporting each other and learning to cooperate as democratic citizens (Hopkins 2003; Morrison 2007). No society can accomplish a transformation to redemptive schooling without overcoming economically irrational underinvestment in education, especially education of disadvantaged children. I say irrational because for decades states have been able to recover a return to GDP of increased education investment that is several times greater than the interest on state borrowing for that education investment. Restorative justice programs in schools struggle for sustainability because they involve work that dedicated teachers are asked to do as an extra gift to the children beyond the teaching that becomes a daily grind for all teachers at times (Burford et al. 2019: Ch. 14).

Education is at risk from neoliberal experiments to create competitive education markets. In countries where test scores determine access to educational opportunities, the educational effort of students can be diverted away from schools that educate a whole person. Instead, they sometimes put most of their effort into the 20 hours a week their parents pay for them to slave away in colleges that groom children to maximise test scores. As education becomes more commodified, private schools can show paths to new forms of educational excellence, but test-score factories can be new markets in bads. Universities are also becoming factories that commodify scores of various kinds for the education market. Increasingly, students become participants in this market in the vice of credentialism rather than in a virtuous pursuit of learning. Not in all respects, but 
for the most part, credentialism is a profoundly less worthy thing than learning how to learn. This is because credential markets require constant change. Education systems will never be good at keeping pace with the specificities of technological flux, but they can be good at promoting learning how to learn and how to lead from below. At all levels, only transformed regulation that moderates credentialism and quantitative indicators (particularly those based on test scores) is needed to ensure that markets in the vice of education factories do not dominate markets in virtue.

On the positive side, today in western universities there are more young women than men. American Ivy League institutions have many scholarships for poor students that they did not have a century ago, and many have senior faculty of colour. Affirmative action self-regulation and state regulation have delivered this kind of result in many countries. School education is also less violent, if not less exclusionary-a result that is directly important for crime control, because the evidence discussed in Chapters 4 and 5 suggests that physically brutal schooling with degrading initiation rituals has been a form of socialisation into violence and militarisation. The school bully becomes the workplace bully, the cyberbully, the war criminal, the genocidaire and 'ecocidaire'.

\section{Social capital}

Social capital is defined here as the structures of social relationships and social beliefs ${ }^{5}$ that have productive benefits as well as being a social resource. This definition is broad enough to capture the features of the most influential definitions of social capital by Bourdieu (1986), Coleman (1990), Putnam (1995), Fukuyama (1995) and Inglehart (1997). Social capital is widely thought to have bonding elements among people with shared beliefs and bridging elements that connect diverse peoples (Putnam 2000; Dekker and Uslaner 2003). We have already seen that Confucian philosophy has elements that fit what today might be called social capital. Bonding and bridging combine with reciprocity norms to build social cohesion, linking capital that has both communal and economic benefits (Hong 2016). Like the World Bank, I conceive of linking capital here as institutional mechanisms that diffuse trust and dialogue

5 Beliefs are defined broadly to include attitudes, values and widely shared norms. 
among institutions. As with human capital, social and financial capital are mutually constitutive. Social networks that are bonded and bridged allow the improvements in state and civil society governance that come from networked governance (Sørensen and Torfing 2016; Braithwaite et al. 2012). The core institution of the social capital literature is that goodwill among people that is built by social capital is a resource that assists the formation of financial capital, richer social relationships in civil society and therefore richer human capital and improved governance of the society.

These broad benefits might raise questions about the wisdom of using a concept (capital) that comes from the narrower economic tradition of thought. Relational goodwill formation may have been a better label than social capital formation. I choose, however, to go with social capital as the concept around which such a rich theoretical and empirical literature has developed. Besides, it is capitalism that future generations must transform if they are to survive.

CHIME (Connectedness, Hope, Identity, Meaning and Empowerment) is that cluster of social relationships and social beliefs that constitutes the subset of social capital that David Best called recovery capital. Best picked up the concept of CHIME as a way of summarising what is central to mental health recovery in meta-analyses (Leamy et al. 2011) and then applied it empirically to recovery from addiction and crime (Best and Laudet 2010; Best et al. 2015, 2018; Best 2017; Hall et al. 2018). The importance given in the CHIME literature to recovery from problems like alcoholism, drug addiction or a period in prison is also important to restorative capital, as discussed in the next two sections.

Trust is the most prominent dimension of social capital in the literature, though certainly not the only one (Braithwaite 1998). Hope is another dimension of social capital when it is collective hope with many of the virtues of trust that helps citizens survive war, unemployment, environmental catastrophes and anomic disruption of normative orders (Braithwaite 2004). Trust is both a social belief and a social relationship. When people trust each other in an economy, transactions are settled with lower transaction costs and with less monitoring, less auditing and less litigation for breach of trust. This is how social capital makes capitalist economies strong. 
Social capital, human capital, recovery capital and restorative capital are unlike financial capital in that they are not depleted through use. When you spend your money from the bank, you deplete your capital. When you trust someone, you do not deplete trust; trust tends to be reciprocated and this engenders virtuous circles of trust-building. A politics of hope is likewise redemptive as we face adversity; it is infectious. In the same way, human capital is not depleted through use. When you use new human capital or recovery capital skills, this sharpens them, nourishes their future growth and allows others to learn from your use of your human capital. CHIME is not depleted through use; it is an investment that grows on its dividends. When we do restorative justice well, many want to do more of it. This is an old insight from Juliet in Act 2, Scene 2 of Shakespeare's Romeo and Juliet.

My bounty is as boundless as the sea,

My love as deep. The more I give to thee,

The more I have, for both are infinite.

The evidence that social capital is important to crime control is considerable. Bob Bursik's (1999) research with various colleagues established a negative association between the social capital of communities and crime rates. Cross-nationally, Lappi-Seppälä and Lehti (2014: 188) showed that increased social trust is associated with reduced homicide rates. Marc Ross's (1985) multivariate analysis of data from 90 smallscale traditional societies showed that violence inside the society was low when there were strong crosscutting ties, meaning strong political links among communities and the resultant sense of intercommunal solidarity of a mini-league of nations (actually of communities in Ross's data). This means that internal violence is prevented by bridging capital.

Bonding capital, however, made things worse in Ross's (1985) research on small-scale societies. Societies with strong fraternal bonds—mainly strong solidarity ties holding together kinship groups-had higher violence. A simple way to illustrate this dilemma is to point out that in southern US communities where social capital was strong in the particular sense of strong bonding capital among members of the Ku Klux Klan, violence was and is still high. Where the strong social solidarity of an ingroup is mobilised by rejecting an outgroup, social capital promotes rather than reduces violence. Where strong kinship ties make it a matter of honour to exact vengeance against those who wrong one's kin, violent interfamilial violence and blood feuds can become common, as Ross's (1985) data reveal. 
Some, but not many, European societies today still have this problem of strong bonding social capital among kin causing blood feuds and a male honour culture-for example, Kosovo and Albania (Marsavelski et al. 2018). Residues of collectivist honour cultures producing family feuds that deliver high rates of killing across the generations can even be found in the Appalachian Mountains not far south-west of Washington, DC.

Many developing economies outside Europe and North America still have large sections of the population in the grip of strongly bonded collective honour cultures that require males to use guns that are widely owned to kill a member of the family who wronged their family. Large parts of the Highlands of Papua New Guinea are like this, as are large parts of Pakistan (Braithwaite and Gohar 2014), and this is one reason Pakistan is an extremely violent society (Karstedt 2012a, 2014a). Indeed, this phenomenon remains so strong globally that Susanne Karstedt's data from this century for 67 countries show that collectivist values and authoritarian values are predictors of individual violence cross-nationally (Karstedt 2006, 2015) and state violence (Karstedt 2011b, 2014b). Her research shows starkly the dangers of highly collectivist and authoritarian forms of capitalism for violence, and against freedom (see also Karstedt 2001).

Karstedt explicitly interprets her cross-national results as showing that collectivist values increase bonding capital within groups and nations but deplete bridging capital between groups and nations, risking the deepening of divides between groups and nations (Karstedt 2003). She shows that this particular formation of social capital strengthens lethal violence, organised crime and corruption, particularly in transitional countries (Karstedt 2003). The long-run history of state formation mirrors Karstedt's cross-sectional late twentieth-century results in profound ways. In the historical process of state-formation, states mobilised violence to pacify ever-wider spaces, bonding nations with the Connectedness, Hope, Identity and Meaning parts of CHIME, even if not with Empowerment. These states encompassed widened pacified spaces where violence became progressively lower and long-run widening of pacification was accomplished (Pinker 2011). Yet in the process of widened internal pacification, states clawed at competing national identities that sought to widen their own internal spaces of pacification. In that dynamic, more unified ingroup national identities that prevented internal violence were accompanied by divisive outgroup identities. These outgroup identities 
were often identities pushing alternative visions of state boundaries that competed with our own. This is part of what Tilly (1975: 42) meant when he said 'war made the state and the state made war'.

Karstedt's data incorporate one clue as to how to keep the knot of internal unity strong while untying knots of hatred towards outgroups. This is her finding that it is the combination of collectivism and authoritarianism in patterns of cultural values that risks violence. Collectivist and authoritarian cultural patterns characterise societies with authoritarian state regimes and high homicide rates in Karstedt's data. Collectivism is benevolent when it is nested in ever-widening circles of identity to village, province, state, continent and as a citizen of all humankind. And it is benevolent when it rejects authoritarianism. Put another way, social capital is put into play in competitive struggles, just as are financial capital and human capital. Markets in social capital vice are not nested in more encompassing identities of inclusion and nondomination. Markets in social capital virtue become ever more inclusive, as banking networks historically have done, despite all their other vices (Burrough and Helyar 1991). Virtuous social capital cheers for the town's or the nation's team in a football match, but also cheers for the bridging bonds of sport that bring nations together in a World Cup or an Olympic Games, and even enjoys the accomplishments of other teams that win competitions against the home team. We all understand how this identity politics of sport can be nested in ways that reject a violent outgroup politics of the crowd, through friendly banter with opposition fans, building both bonding and bridging capital through the institutions of sport. The same nested nationalisminternationalism has played out at the World Trade Organization (WTO), where states stuck together to win good deals against other states, but also bridged with those competitors to defend the institution of the WTO as one that could put boundaries around that very competition. Families are rather better at this than states, though not always - that is, families are mostly good at sustaining their own bonding capital while respecting the role of other families to build their own bonding capital in their own way, building bridges to them without expecting other families to do as much for our children as we do for our own.

Hence, an important interim conclusion here is: not only are there markets in vice and markets in virtue, and in good and bad financial capital. There is also good and bad social capital, where good social capital is nested and anti-authoritarian, rejecting the domination of outgroups. While we did 
not discuss this explicitly in the human capital section of this chapter, obviously there is also good and bad human capital. The human capital induced by certain religious schools to have the piety, determination, self-sacrifice and resilience to be a suicide bomber is an obvious example of a bad form of human capital. Training bankers to be ruthless profitseekers with no regard for commercial ethics is another.

More generally, all forms of capital formation can constitute markets in vice or markets in virtue. They can constitute violent, grasping cultures or nonviolent, generous cultures, locally and globally. We will see that even a form of capital that I have tended to characterise as virtuous, restorative capital, can and does contribute to oppression when its values are not clarified and when restorative justice is not enacted carefully to focus on inclusion and nondomination. Frankly, value-free positivist research on social capital has limited use for these reasons. This argument is pushed a bit further in Chapter 11, where it is suggested that one reason collective efficacy may be the form of social capital that best explains crime is that it is not a value-free conception.

Another important way of reading Karstedt's results is to focus on their reverse side: the result that homicide is lower in societies with a combination of strong individualism and strong egalitarianism in their cultural patterns (Karstedt 2001). This leads us not only to emphasise the importance of egalitarianism and nondomination through comparative equality, but also the importance of societies that constitute strong individuals. Structural equality, Karstedt concludes, is a strong predictor of high levels of generalised trust in a population. It is in inegalitarian, collectivist societies that people cling to their ingroup, failing to build trusting relationships with the other. Trust becomes generalised in its capability to build all forms of capital when individuals are strong and embedded in egalitarian cultural patterns that enculturate trust. This is the enculturation of trust versus institutionalisation of distrust theme we return to in the conclusion and throughout this book. Individuals who do not learn to trust never acquire the agency that is the stuff of making the personal political. At the microlevel, this book argues for restorative practices that empower the agency of strong individuals not only in the justice system, but also in families, schools, businesses and governance. 
Reintegrative shaming theory can also be deployed to help sharpen the conceptual differences between good and bad social capital. Social capital prevents crime when it is reintegrative in its relationships with outgroups; social capital accelerates mobilisation for crime when it is stigmatising in its relationship with outgroups (Braithwaite 1989). That means respect and dignity being granted to outgroups and to those who wrong us. It means a politics of inclusion towards our enemies, be they family enemies, criminals or enemies of our religious group, ethnic group or country. In sum, whether social capital is a good or a bad thing in terms of crime prevention depends on eschewing the politics of stigmatisation through bridging capital that beats a path to a politics of inclusion. Valerie Braithwaite (2009b) would say it requires balances between security values (values about keeping us safe) and harmony values (values about a broadened politics of love and inclusion). Without that balance, we are at risk of being exploited by others or being the exploiters of others. We must be discriminating about what modalities of social capital might be protective against crime for communities (like collective efficacy, which we will now discuss). And we must be discriminating about which are dominating modalities of social capital, such as those constituted by the 'greed is good' subcultures of Wall Street.

Diverse studies now suggest collective efficacy may be the form of social capital that performs particularly well in protecting communities from crime (for example, Odgers et al. 2009; Hipp and Wo 2015). This may not be true in China (Zhang et al. 2017) where, perhaps, collective efficacy too often falls into Karstedt's authoritarian trap of being deployed to enforce domination by crime and by the state rather than freedom from crime and from the state (see Chapter 2). This danger is inherent in communal institutions that simultaneously secure the normative order of community safety and the order of party domination. Collective efficacy is a more specified form of social capital, an actively engaged form of community capital, which prevents crime in the West. Sampson et al. (1997: 918) define collective efficacy as 'social cohesion among neighbors combined with their willingness to intervene on behalf of the common good'. Collective efficacy that prevents crime is certainly a set of 'social relationships'; social relationships that make a community safer also have productive benefits because investment avoids unsafe environments. Collective efficacy is more than the sum of individual self-efficacy (Bandura 1986, 2000) in that it is also about hospitable social solidarity. 
Our research team has shown empirically that collective combined with individual self-efficacy helps managers of organisations prevent regulatory offences by making corporate compliance systems work (Jenkins 1994). Hence, this form of social capital is relevant to preventing crime in the suites, just as it is to preventing crime in the streets (Braithwaite et al. 2007: 307-18). Interestingly, from the perspective of republican political theory, Bandura (1989: 1182) sees self-efficacy as defining freedom 'in terms of the exercise of self-influence'. Collective efficacy is also liberating for individuals who participate in it because it involves collective empowerment, including collective empowerment to resist domination. Bandura's self-collective efficacy view of freedom is at one with Amartya Sen and Martha Nussbaum's capabilities approach to freedom-that is, freedom as capabilities to enjoy the kind of life individuals have reason to value. An important part of such capabilities that can be destroyed by low income, among other things, is 'freedom to act' (Sen 1999: 86). This freedom to act as capability might alternatively have been conceived of as self-efficacy and collective efficacy as capabilities and freedoms to act.

Sampson et al. (1997) and Morenoff et al. (2001) found that greater race and class segregation in metropolitan areas meant smaller numbers of neighbourhoods absorbing the economic shocks of deindustrialisation and a more severe resultant concentration of poverty. I have argued that class segregation has long been associated with increased crime, and there is a long-demonstrated multiplicative, as opposed to additive, relationship between class and class segregation in their combined effects of crime (Reiss and Rhodes 1961; Braithwaite 1979). Deindustrialisation accelerated class concentration and its effects on the 'truly disadvantaged' (Wilson 2012). Sampson et al. found that the effect of class and race concentration in increasing crime rates is partly mediated by declines in collective efficacy. The geographical concentration of the collective loss of hope and meaning might also heighten a subjective sense of exclusion.

Local communities are better able to go about the business of building a neighbourhood with collective efficacy if distrust is institutionalised through a capacity to call in police who are trusted. A job of civil society in the good society is to enculturate trust through collective efficacy; a job of the police is to institutionalise distrust of criminality when there is 
a serious enough breach of community trust. ${ }^{6}$ Of course, this division of labour fails when police in disadvantaged communities do not believe that black lives matter.

In Chapter 11, we will see that just as crime, violence and anomie are cascade phenomena, so is collective efficacy. When you spend social capital in the form of collective efficacy, this sends wider ripples of collective efficacy across society's pond.

\section{Recovery capital}

Groshkova et al. (2013) showed that recovery capital can be measured with acceptable concurrent validity and test-retest reliability that distinguishes it from social and human capital (see also Sterling et al. 2008). This result is not inconsistent with our conception here of financial, social, human, recovery and restorative capital being mutually constitutive when they eschew domination. Recovery capital prospectively predicts desistance from drug abuse and predicts life satisfaction (Laudet and White 2008; see also Mawson et al. 2015). Recovery capital is defined as structures of social relationships and social beliefs that have recovery benefits as well as being a social resource. Networks of social support are critical resources of recovery capital (Best et al. 2012). White and Cloud (2008) conclude from their review of the evidence that recovery is more about capital (the presence of strengths) than the absence of pathologies. Most recoveries from addiction need dollops of social support and collective hope as social capital because, ultimately, desistance from abuse is almost always preceded by a considerable number of concerted failed attempts at desistance (Laudet and White 2008). Recovery communities that constitute recovery capital are an important concept in this work.

Criminology has made a formidable contribution here, even when it does not use the language of recovery capital. Best and Laudet (2010) summarise the criminological literature as having a large overlap with what has been learned about recovery from mental illness, alcoholism,

6 Braithwaite (1998) developed the idea of the good society as one that enculturates trust in the foreground of social life and institutionalises distrust in the background. It builds on Yamagishi and Yamagishi's splendid Japanese program of research showing that a culture of trust builds social intelligence. One must learn from the culture how to take the risk of trusting others, learning about judgements of which contexts and people are trustworthy (Yamagishi 2001). These ideas will be further developed as this book proceeds. 
overeating and various other non-crime problems. Best and Laudet (2010) approvingly cite Laub and Sampson's (2003) overview of what we know about desistance from crime as being central to what we know about recovery more broadly:

- attachment to a conventional person (spouse)

- stable employment

- transformation of personal identity

- ageing

- interpersonal skills

- life and coping skills.

Shadd Maruna's (2001) work on Making Good through redemptive scripts discovered implications for building recovery capital through programs that put old offenders who had made good, who had re-narrated themselves, into networks with younger criminals who have not learnt how to re-story their criminal career in a redemptive way. Evidence for this has since grown stronger (for example, Laudet and White 2008). Recovery capital scripts can be even simpler. Kenneth Polk (1994) found that young men convicted for murdering other young men had never learned that when one accidentally bumps into a person carrying drinks in a bar, it is best to say, 'Excuse me'. No-one had taught Polk's young male-on-male violent offenders such simple scripts. Recovery from something as terrible as conviction for a pub homicide can be assisted by these young men concluding, 'No, I am not an irredeemably violent person, but I am a man who needs to learn certain simple rituals of civility to become a more polite person.'

The most important findings from meta-analyses of recovery from a diverse range of dreadful life challenges-including mental illness, drug addiction, alcoholism and a criminal conviction — are that CHIME (Connectedness, Hope, Identity, Meaning and Empowerment) precedes recovery (Leamy et al. 2011; Best and Laudet 2010). Beyond access to the recovery version of social capital, access to economic capital is also important to recovery, particularly in the form of secure housing. This literature suggests that many interventions that are effective for people in secure housing are not effective for those without secure housing (Cano et al. 2017). This is so much the case that secure housing is an integral part of the scale to measure the recovery capital construct (Best et al. 2012; Groshkova et al. 2013). 
Alcoholics Anonymous (AA) has an interesting strategy for scaling up recovery capital. Its step 12 is to pass on the gift of recovery, to help yourself by helping other alcoholics to learn the lessons to re-story themselves to recover. This happens at scale through 106,000 AA groups across 150 countries around the world. Chapter 11 argues that there is an AA insight here that might be applied to the challenge of cascading recovery capital, restorative capital and collective efficacy more broadly.

Clifford Shearing and Richard Ericson (1991) realised that organisations as well as individuals can be re-storied. They argue that police culture is a storybook rather than a rulebook. Changing a police organisation requires changing the stories police share about good policing in the lunchroom and the patrol car. It is also possible to re-story a nation. We have discussed how Nelson Mandela did this for South Africa, reassuring whites with the message that whether citizens were black, white or coloured, to be a South African was to be a victim of a terrible institution called Apartheid (Meister 1999). Likewise, Abraham Lincoln at Gettysburg redemptively re-storied a nation-a scaled-up form of narrative therapy for a nation. Whether South or North, black or white, Americans are all people who suffered from slavery as an institution. It was a noble meaning for the American identity to be one of struggling continuously against the violence of slavery; and for South Africans to be engaged with a lifetime struggle to purge the nation of the violence of Apartheid (Meister 1999). This is the nobility of recovery capital.

\section{Restorative capital}

Restorative capital is like recovery capital in being a form of social capital that is a relational resource constituted by a relational practice (relational restorative justice) (Llewellyn 2012). My big-picture proposition here is that societies that are more holistically just are likely to have less crime and less armed conflict. Societies that have more social justice, more procedural justice, more gender justice and more restorative justice are likely to be less violent. People with special gifts in how to communicate to others love, understanding, compassion, empathy or spiritual depth in a restorative justice circle are those with the most restorative capital for building all these kinds of justice. They have gifts in how to cascade relational gestures of healing around a restorative circle. Relational justice allows relational enforcement of recovery agreements. The Canadian 
Department of Justice's meta-analysis of the effectiveness of restorative justice by Latimer et al. (2001) found that the biggest effect size was not related to the direct power of restorative justice to prevent crime, though that was statistically significant. It was the superior capacity of restorative justice to achieve compliance with restorative agreements to help victims. Control groups in which reparation to victims was ordered (for example, by a judge) accomplished less delivery of reparation to victims than cases where reparation was volunteered in the restorative circle. The superior enforcement power of restorative justice in getting compliance with restorative agreements is mediated not by the police, but by friends and loved ones at the restorative conference who commit to monitor and ensure compliance with the agreement they participate in defining. A special capability of restorative justice is that it is a superior delivery vehicle for securing compliance with and commitment to rehabilitation and future prevention interventions that work (Braithwaite 2002).

So, we need not think of restorative justice as a micro-intervention. It is macro in two ways. First, restorative justice institutionalises spaces such as restorative circles and restorative city networks in which all manner of more micro-interventions are given a better chance to work than they are given by judges ordering them or prisons institutionalising their captives. Second, restorative justice is a social movement that is about justice and that has things to say about big injustices-for example, the injustice of the financial crimes of the Global Financial Crisis and how they might have better been addressed and prevented (Braithwaite 2013a). Braithwaite's (2000) conception of restorative justice does embrace advocacy of social justice and, more widely, it advances social movement advocacy for a transformed normative order compared with the order embedded in extant criminal legal systems (Braithwaite 2002) —an order that emphasises healing and prevention with safety, deep listening and empowerment.

For many Christian, Jewish, Muslim, Buddhist and First Nations advocates of restorative justice, it is a spiritual social movement that goes deeper than the values articulated above. I am a spiritually shallow person for whom religious social movements hold little appeal. Yet my empirical experience of observing many restorative justice circles is that when a 'spiritually deep' person is in the circle, this does gently spread a contagion of care across the circle. I once said to Chief Justice Emeritus Robert Yazzie of the Navajo Nation: 'I do see that spiritual contagion in the circle from indigenous leaders with mana, but I am a spiritually 
shallow westerner. So, how can I learn from your indigenous wisdom?' I expected something like, 'You have no hope, white man.' But no, the wise Navajo leader said I could achieve personal spiritual deepening by taking my heart to a place in nature I most love-a place that resonates with my identity and my ancestors and takes me out of myself. I have taken that advice these past 20 years and I do improve as a person when I take myself to my loved spotted gum overlooking the Pacific Ocean. I hug that tree regularly! There is strong evidence now that spiritual belief and spiritual activities can give hope and strength and provide meaning, especially during times of stress (for example, Galanter 1997); can prevent substance abuse, especially of alcohol and cocaine (Bakken et al. 2014); and are associated with desistence from crime in crosssectional studies, though less so in longitudinal data (Giordano et al. 2008). Randy Martin (2000) even speaks of the evidence that spiritual alienation as anomie contributes to crime. Underwood and Teresi (2002: 31) describe this as 'social support from the divine'. Indigenous people often fear spiritual enforcement after a breach of a restorative agreement 'after the stone is buried'. After Breaking Spears and Mending Hearts (Howley 2002), hearts stay mended for fear of breaching an agreement that implies sacred enforcement in various parts of Indonesia, Timor and Melanesia (Braithwaite et al. 2012: 216-23). The literature shows a strong and consistent inverse relationship between spiritual wellbeing (a multidimensional construct that incorporates existential wellbeing or life meaning and spiritual beliefs) and psychosocial wellbeing of diverse kinds (Ellison 1991). For criminologists, however, the evidence remains unsettled on whether the notable effects on offending rates are the preventive effects of spirituality or the social support and other benefits of being religious or churchgoing (Jang and Franzen 2013; Johnson and Jang 2011; Dilulio 2009; Baier and Wright 2001). Put another way, are these effects about the Connectedness or the Meaning facets of CHIME?

Restorative capital is constituted when large numbers of children have experiences of these values in their families and schools, and then later in their life in primary workgroups. The evidence is that social capital ripples out more strongly and more broadly from primary groups of familyschool-work than it does from intermediate civil society organisations, though these are also important (Job and Reinhart 2003). In other words, restorative justice in the criminal justice system is a second-order reform for crime prevention and building freedom compared with restorative justice in families, schools and primary workgroups. What do I mean by 
saying that primary-group restorative capital is important for building freedom and not just for preventing crime? Children are not born free; they are not born democratic; they are born dependent and powerless. Restorative justice circles in families and schools can be venues where children learn to become democratic, how to become free citizens who can resist domination deliberatively. In other words, the hypothesis is that a society that invests in restorative justice takes a macrocriminological step towards constituting social capital, and therefore towards crime reduction.

\section{Mutually constitutive variegations of societal capital}

Braithwaite (2013a, 2019) argued in a detailed way for the implausible counterfactual that restorative capital could have been deployed preventatively before the Global Financial Crisis occurred. Some details of these regulatory reform arguments are discussed Chapter 10. Their implausibility or plausibility need not delay us in this chapter. The example is signalled to illustrate the general point that when all the foregoing forms of capital are strong and more justly distributed, they can be mutually constitutive and each can be mutually tempering of the power of the other. Furthermore, this is fundamental to preventing cascades of crises that include financial crises, ecological crises and wars. If our accounting schools do not produce professionally competent and ethical accountants as a crucial pillar of our human capital, financial capital will not flourish. Likewise, if trust and collective efficacy do not flourish on Wall Street and in the City of London, embezzlement will flourish. Without trust and collective efficacy on the street, financial capital corrodes and collapses from within. While the idea of collective efficacy comes from the streets of Chicago, we saw it on the streets of the financial City of London and on Wall Street a century ago at times when Baron Rothschild in London and J.P. Morgan in New York would act to prevent a run on a bank by marching to the front of the frenzied queue of customers waiting to make a withdrawal and ostentatiously deposit a huge pile of Rothschild or Morgan cash into that teetering bank (Braithwaite and Drahos 2000). This indeed was social cohesion of the financial street 'combined with their willingness to intervene on behalf of the common good' (Sampson et al. 1997: 918). The best ethnographies of Wall Street, such as Barbarians at the Gate (Burrough and Helyar 1991), have been written by experienced financial journalists who aimed to reveal the ruthless fabric of the street. 
Yet a social fabric they do reveal is that Wall Street and the City of London are financial communities with communal qualities frequently affirmed by rituals of apology, forgiveness and reconciliation, even if rarely by fully repairing the harm done!

In Burrough and Helyar's (1991) rich ethnography of the greatest takeover up to that time, the battle for RJR Nabisco, the following passage shows Henry Kravis, the pre-eminent investment banker who won the takeover battle, acting to affirm the importance of ceremonies of reintegration in the Wall Street investment community:

Wall Street is a small place, and in the interests of harmony Kravis wasted no time healing wounds inflicted during the fight. He made peace with Peter Cohen at a summit in February and actually hired Tom Hill to investigate the possible takeover of Northwest Airlines ... Kravis also moved to smooth relations with Linda Robinson. Soon after the Gerstner episode, Linda took a message that Kravis had called. She ignored it. Within days she received a small ceramic doghouse with a cute note from Kravis, suggesting he was in the Robinsons' doghouse. Linda Robinson waited a few days, then sent Kravis a twenty-pound bag of dog food. All was forgiven. She and Kravis still own 'Trillion'. Fees, of course, went infinitely further toward soothing Wall Street's wounds ... Kravis even spread the largesse to those whose feelings he might have bruised. Geoff Boisi's Goldman Sachs got the job of auctioning Del Monte, while Felix Rohatyn's Lazard Freres did the same for the company's stake in ESPN. (Burrough and Helyar 1991: 508)

These may be vulgar modalities of reintegration, yet they are practical means of nurturing vulgar communities of commercial excess. A standard observation in the business culture literature is that the City of London was historically much more communitarian than New York (for example, Wechsberg 1966: 41; Coleman 1990: 109). Clarke's (1986) book on the City of London was about the imperative for a shift to more formal regulation of the city because Wall Street 'cowboys' and other rapacious internationals like Rupert Murdoch and Conrad Black did not quite understand that they were being allowed into a gentlemen's club where 'a word is as good as a contract'.

The storm of the Great Depression was too great for even the reparative power of the Rothschilds and Morgans to mobilise collective efficacy on the street. Instead, it proved necessary from the 1929 experience to 
institutionalise distrust in bank imprudence through regulatory agencies that accrued ever-greater powers in the century since. Wall Street needs CHIME after it crashes. It needs connectedness on the street that can incubate new networks of trust. It needs realistic collective hope that recovery is possible. Wall Street needs a sense of identity, meaning and empowerment after a crash that has devastated its confidence and the self-efficacy and collective efficacy of its traders and its institutions. Unemployed traders need to recover the meaning they get from a job. On the ashes of the unethical trading that causes crashes like that of 2008, traders need to find a new professional identity and a new ethical meaning in their business lives that are connected to their redemptive responsibility to unfreeze lending and rebuild confidence in a more genuine integrity of markets so that the unemployed might find jobs. Some of the most successful investors of financial capital, like Warren Buffett, have been recurrently good at this as they survived one crisis of capitalism after another. Recovery capital as well as restorative capital are critical to rebuilding devastated capitalist markets after a crash.

Strong institutions for building human capital, social capital, recovery capital and restorative capital are also needed to check and balance economic capital. Without constant growth of economic capital, longterm unemployment is the result. Chapter 4 showed this is a crime risk. Yet, some shifts from private to public capital are also needed. An example is that the European Union might have established a public European ratings agency to contest the fraud of the major US private ratings agencies seen during the Global Financial Crisis. The crimes of Deutsche Bank during that crisis could have been sanctioned by 'capital' punishmentan equity fine in shares of the company, as discussed in Chapter 9-rather than a massive cash fine. Averting climate change catastrophe will not be achieved so much by punishing environmental criminals as by shifting capital from carbon to solar and hydrogen, and cars from petrol power to electric power. Then the fuel economy crimes of corporations like Volkswagen become less important.

Financial capital needs more checking than service-sector capital because banking is the most aggrandising and the least humble form of capital, and the most criminogenic. That means an imperative for freedom and crime prevention is the regulation of markets in goods and markets in financial bads. Criminal markets are conceived of as markets in domination, in unfreedom, whether they are markets in financial fraud, corruption, buying politicians with hidden campaign contributions, illicit 
drugs, fake Covid-19 vaccines, prostitution, organ trafficking, trafficking in endangered species or modern slavery. This chapter has argued that new sustainable markets are vital for rebuilding all forms of capital in devastated cities like Detroit because such cities can be seedbeds of transformation from neoliberalism to authoritarianism and thence to future crime-war cascades.

\section{Creatively balanced capitalism}

Capitalism has a mystique that suggests private capital is the creative engine that drives forward all innovation. Economic capital certainly is important to driving creativity, but of an importance frequently exaggerated by those who ignore our other forms of capital.

Consider food production, the most important productive activity humans do. Three-star Michelin restaurants cultivate the mystique that their chef keeps his secrets so we must go there. In practice, this is impossible as staff the chef mentors move to other restaurants where they might improve on those supposed secrets. They might decide to become even more famous than their mentor through a television show in which their recipes are shared. Most historical innovation in the production of food has occurred in non-market household economies; this is the intellectual property that three-star restaurants usually purloin. Women's labour for millennia experimented with new foods and new recipes. Women shared their recipes. Sharing accelerated when cookbooks - often assembled by women's organisations such as church groups-were enabled by new technologies of printing. The internet and television further accelerated the sharing of women's unremunerated human capital in feminised food innovation. Older readers appreciate how steep this acceleration has been. Before television, our experience of food was monotonous, monocultural. Change was driven by creative balance between the unpaid innovation of our mothers and its propagation in cooking columns and books. Growing wealth in service economies meant that, by the late twentieth century, we could afford to dine at restaurants where food was cooked by someone other than our mothers. Feminism enriched diversity in the human capital contribution to family food; sometimes there would be turn-taking of meals prepared by fathers or brothers. The human capital market in chefs was captured by men; it drew on men who had been active in family food preparation. 
In sum, the massive surge in the creativity of food preparation in recent decades is a product of creative balance between market capitalism, the globalisation of emulated food innovation driven by the emergence of mass media and social media, the human capital of women, the community capital of the church cookbook and the social capital of feminism as a social movement that brought more celebrity female chefs to the fore. One might say the state had little to do with it. State-funded technical colleges did train chefs to special forms of culinary excellence, but this was hardly the main game. The problem today is that food innovation is no longer making us better off because state regulation is not playing a big enough role in food industries that have become overly commodified. The progressive struggle has been one of bringing more of the human capital back into food to supplant that takeover of factory food that is a market in vice. In sum, even the most important productive endeavour for the flourishing of humankind is not fundamentally an accomplishment of markets and, when the market did become more prominent, it was more a market in vice than a market in virtue.

The role of the state was always of more importance than people could see. As restaurants took off, fly-by-night cooks who cut corners on the freshness of their food proliferated under the protection of the anonymity of large cities. All states and local governments had to hire food inspectors. This improved things. Even so, millions of people suffer food poisoning that makes them awfully sick (and kills formidable numbers of them) every year in every society. Food poisoning is possibly the only crime of capitalism that virtually all of us suffer on multiple occasions during a lifetime. Criminology is myopic in the way it almost ignores food poisoning as a crime, merrily persisting with the fiction that crimes like theft are more important than food crimes-and more important by ratios of thousands of articles on theft to each one on food crime in criminology journals.

Poisoning by rotten food is not the most important harm of culinary capitalism. Imbalanced commodification of global processed food means that consumption of the same deadly cans of cola is a global pandemic. Commodification of sugary foods by processors and of fatty foods by global fast-food chains of Donor McDonor capitalism have built an obesity epidemic. This epidemic is a greater killer than Covid-19 or the cancer caused by the commodification of tobacco or alcohol. Japan is the developed economy least afflicted with obesity, where people live longer because it has been most resistant to global food. Although 7-Eleven 
stores can be easily found in the vicinity of international hotels in Japan, the food in their refrigerators is different than in other countries. More of it is unprocessed, fresh Japanese fare such as sashimi prepared by humans.

Hence, the creative balance of food production has tipped too far towards commodified food. This is a similar point to the claims made in the discussion of human capital about how the creative balance of education production has tipped too far towards commodified education. Now we realise that we were better off with the food that preceded the accomplishments of feminism in projecting women's human capital into food markets; children were better off with the food produced by the unpaid domestic labour of their mothers. The policy remedy here of course is not to reverse the gains of feminism but to accelerate the regulation of food markets by means such as sugar taxes and by investing in human capital that enculturates resistance to sugar; teaching boys as well as girls about fresh food preparation in primary school, in the mass media and on the internet, so the human work of preparing wholesome food is shared.

Untempered commodification of food profoundly worsens inequality. Markets in bads have become so efficient that processed food, fast food, fat and sugar (once a luxury) have become supremely cheap. They are cheap ways for hungry poor people to fill their stomachs. Repeatedly eating potato cooked as fries or processed crisps boiled in fat may be low-cost, but with long lags, this makes health and lives a misery. Poor nutrition has become a major structural driver of inequality. Poor health and visible obesity ultimately also affect the employability of the poor as they get older, reducing their ability to move their children to better circumstances.

Hence, food crime is directly responsible for widespread corporate homicide by food poisoning; imbalanced commodification of food is responsible for inequality that indirectly increases crime in communities sickened and impoverished by commodified food-less so in Japan, Italy or France, but more so in the societies most afflicted by global food. This is even more true in parts of those societies such as the workingclass communities of Glasgow, where deep-fried fare flourishes and sugar surges, and where those who live in the city's middle-class suburbs live 28 years longer than those in working-class areas (Marmot and Friel 2008: 1096). 
The most deeply structural conclusion of this chapter is that capitalism helps us to flourish and enjoy low-crime societies when financial capital is balanced by human, social, recovery and restorative capital. Food has been used to illustrate the more general phenomenon that unbalanced domination of money capital corrodes the creativity of human society. It is ultimately self-defeating because of its own contradictions of commodification. This was the brilliant and enduring insight of Karl Marx that sat alongside his many less-enduring insights that stemmed from the oppressive idea of a dictatorship of the proletariat.

Writing before the regulatory state rose in Victorian England (MacDonagh 1961), Marx failed to see how a regulated, mixed and balanced capitalism had the potential to regulate its crises, to sustain its creativity and to clear the smog from its cities by controlling environmental crimes. Still, Marx's enduring insights mean there is no inevitability that the human species is capable of rebalancing capitalism to prevent it from destroying our civilisation and our planet. Burgeoning commodification causes so much corporate and common crime because it is so dominant a structural force that it sometimes proves beyond our capacity to tame. Even if we succeed in saving the planet by punishing corporations that cheat on obligations to reduce carbon emissions, at some future point in history some state criminal, some mentally unstable military official with a finger on a button or a terrorist may destroy the planet by triggering a cascaded exchange of weapons of mass destruction after which safe crops will no longer grow across large swathes of the planet. The challenge of struggling to make this prediction false by effective regulation of capitalist markets in weapons systems, killer robots, carbon and deadly food is the challenge for human survival. Ultimately, humans are likely to fail at this challenge, but if the next generation builds sounder institutions of nondomination, extinction can at least be deferred for centuries. A criminology of capital formation for organisational crime prevention is at the heart of this politics of hope.

\section{Dangers of trust in capital formation}

To build social capital, we must enculturate trust. Trust is enculturated in civil society through the educative stories of families and schools on the virtues of trustworthiness, through the actual granting of more trust to children as they grow and through nurturing pride in virtue by honouring trust as an obligation. Hence, human capital formation in the 
education system both creates trust and depends on trust-as do recovery and restorative capital formation. Douglass North has contended that secure property rights and trust nurtured by merchant codes of behaviour enabled a striking decline of interest rates in the Dutch capital market of the seventeenth century and then in the English capital market in the early eighteenth century (North 1990: 43). There is an open debate, however, over whether it was the moral force of such codes or the monitoring and use of sanctions they enabled that was the more important influence (Greif 1989). Perhaps there was a bit of both.

Robert Putnam (1993) has shown that fabrics of trust arising from rich traditions of civic engagement characterise the regions of Italy that flourished economically and subdued the Mafia throughout modernity. Furthermore, the more economically backward regions, where distrust dominates, are also the regions where political corruption festers. Putnam was methodologically deft in showing that the direction of historical causality operating here was not that economic success generated a trustbased culture but that a strong fabric of trust, woven in strong institutions of civil society, had economic benefits. Putnam's results are the most tantalising empirical evidence we have that resilient trust simultaneously limits the abuse of power and expands economic growth. Putnam's work shows how we can be both freer from want and freer from organised crime and corruption when social capital is in plentiful supply. Yet undersupply is standard, unfortunately, because we all have an interest in free-riding on the efforts of others who work to build a rich civil society. Trust creates more wealth to tax and causes people to pay their taxes more honestly. Trust, for Putnam, is the most important feature of social organisation that facilitates coordination to solve collective-action problems. Putnam (1995) has also shown across 35 nations a strong positive correlation between 'social trust' and 'civic engagement' (the density of associational membership). Networks of civic engagement are where trust and norms of reciprocity and cooperation are learned and enculturated. Enculturating trust is a technique for controlling the abuse of power that not only averts a major drag on economic efficiency, but also actually increases efficiency.

The problem with interpersonally trusting people and civil societies is that ruthless people abuse their trust. In response to this problem, Braithwaite (1998) argued that the priorities are to enculturate trust and to institutionalise distrust. The crucial way to institutionalise distrust is to temper the power of one strong institution with other strong institutions. The republican dilemma is that while a stronger state risks bigger abuses 
of trust and has more power with which to crush freedom, a stronger state can also do more to increase freedom. The bigger the state budget, the more it can disperse to combat the unfreedom of poverty, for example. Strong states, strong markets and strong civil society (including strong families) are simultaneously the greatest resources we have for building freedom and the greatest threats to it. The challenge of institutional design is to realise fully their potential for building freedom while maximally controlling their potential for destroying freedom. The republican perspective is that we can trust the state to be stronger when there are robust separations of power. A state in which the judiciary is independent and the rule of law is strong can be more powerful than one in which they are not; a state with strong institutions of civil society to exercise countervailing power against the state can be stronger than one in which they are weak. We can allow markets to rule over more domains of resource allocation when state regulatory capacities are strong. When civil society is strong, the jeopardy to freedom from what Jürgen Habermas (1985: 305-96) called 'the colonization of the lifeworld' is checked. A danger of rampant markets is the commodification of things (like food) that better constitute freedom when they take a noncommodified form. Education and research are other good examples. Art is perhaps a more controversial one, given the impetus markets have so often given to artistic innovation. Even so, it seems clear that we can be much more relaxed about market encroachments on art when the elements of civil society that nourish the arts are strong. So long as local folk clubs continued to meet and play around campfires, at family pianos and in little pubs and cafes, we did not need to worry about Bob Dylan topping the charts.

Strong civil society is by no means always constitutive of freedom. Perhaps no institution does more damage to freedom than the domineering, engulfing family. While the prime countervailing power against domination in southern US civil society in the 1960s also came from civil society-from black churches and white college campuses—a strong attorney-general and a strong president who stood in the firing line were also important. We can trust families to be strong only when the state is willing to intervene in families in which women and children are brutally dominated. In comparatively egalitarian capitalist societies, where family monopolies of socialisation are contested by the state education system and electronic markets for information, and where job markets give women economic opportunities to escape, strong families are not quite as troubling as they are in feudal or tribal societies in which markets provide no exits, no counter-socialisation. 
Similarly, there were good reasons to worry about the threat of the church to freedom when markets were so weak and the church so strong that it could dictate who could get employment and who should be denied it based on religious belief. Today, few societies fear another Inquisition. The power of the church to punish is so much more effectively checked by separated powers of the state. Public interest groups and social movements are less likely to become oligarchies when states require them to be run democratically and to respect human rights. Environmental groups are less likely to be captured or corrupted by the very business and state institutions against which they should be exerting countervailing power if their seats at negotiating tables with business and government are contested by competing environmental groups (Ayres and Braithwaite 1992: 54-100).

\section{Beyond neoliberalism and socialism}

Practical politics rarely works to enculturate trust and institutionalise distrust. Neoliberals and libertarians like to totalise their trust in markets and distrust of the state. They want strong markets that weaken the state. Socialists distrust the exploitation caused by markets; they are overconfident in the capabilities of a socialist state; they want a strong state that weakens markets. Incumbents of the institutions of the state and of markets want to weaken the power of civil society because civil society is always criticising the way they exercise their power. In response to this reality, there are some civil society activists, influenced by a mix of anarchist and green ideologies, who want markets to be weaker and the state to be weaker. Likewise, in academia, economists are misguided in seeing civil society as a sideshow because markets are what really matter; public policy scholars and some criminologists are misguided when they see civil society as unimportant because the state is where the action is. By civic republican lights, all these political ideologies are deeply misguided in all these ways.

Republicans, Braithwaite (1998) argued, want an enculturation of trust that enables strong markets, strong states and strong civil society. Because republicanism is a liberal philosophy, it also values strong individuals. This book argues that a strong United Nations also adds critical institutionalisations of distrust that advance freedom in international society. Republicans should not reject all aspects of neoliberalism and 
libertarianism, but they must reject their commitment to weaken a state that needs constant strengthening as a ship repaired at sea. Republicans should not reject all aspects of socialism, but they must totally reject the idea that markets should be weakened; markets in vice are what want weakening. Likewise, republicans must shun suggestions to weaken markets in some interpretations of institutional anomie theory. America's strong markets and strong individuals are prominent strengths, including in the discovery of new technologies for controlling cybercrime and every other form of crime. What we should want politically is to enculturate trust in those strengths while institutionalising distrust from a stronger US state, especially a stronger business regulatory state, and ever stronger US civil society.

These past two chapters have argued that strong markets, a strong state, strong civil society and strong individuals are all vital to more freedom and less crime. Both enculturating trust and institutionalising distrust in all these institutions are imperative. The practical way to accomplish this are prudent and radically pluralised separations of power. That means each institution of separated powers being strong enough and independent enough that it can deliver the trust-building work that is its contribution to the economy, the polity, the criminal legal system and the society. But it also means that its strength must be checked and balanced by the strengths of many other similarly strong institutions in the separation of powers. And it means that no institution-not the presidency nor the supreme court and especially not the military-must be so strong that it can shut down the power of all other institutions. The next chapter argues that when those checks and balances are settled, strong and subject to the continuous strengthening of all institutions, as opposed to unsettled by anomie, the ship of society can better plough through dangerous waters. Societies run on to the rocks when any institution makes a play for unaccountable domination over all others. 
This text is taken from Macrocriminology and Freedom, by John Braithwaite, published 2022, The Australian National University, Canberra, Australia.

doi.org/10.22459/MF.2021.07 